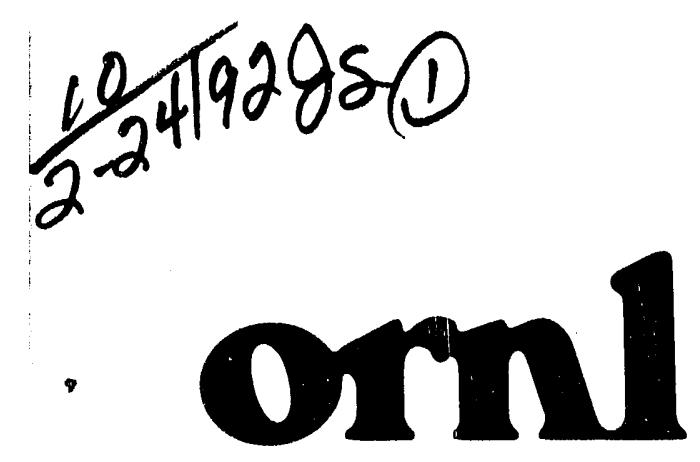

OAK RIDGE

NATIONAL

LABORATORY

MARTIN MARPIETRA

\title{
Treatment Options and Flowsheets for ORNL Low-Level Liquid Waste Supernate
}

\author{
D. O. Campbell \\ D. D. Lee
}


This report has been reproduced directly from the best available copy.

Available to DOE and DOE contractors from the Office of Scientific and Technical Information, P.O. Box 62, Oak Fidge, TN 37831 ; prices available from (615) 576-8401, FTS 626-8401.

Available to the public from the National Technical Information Service, U.S Department of Commerce, 5285 Port Rcyal Rd., Springfield, VA 22161.

This report was prepared as an account of work sponsored by an agency of the United States Government. Neither the United States Government nor any agency thereot, nor any of their employees, makes any warranty, express or implied, or assumes any legal liability or responsibility for the accuracy, completeness, or usefulness of any information, apparatus, product, or process disclosed, or represents that its use would not infringe privately owned rights. Reference herein to any specific commercial product, process, or service by trade name, trademark, manufacturer, or otherwise, does not necessarily constitute or imply its endorsement, recommendation, or favoring by the United States Government or any agency thereot. The views and opinions of authors expressed herein do not necessarily state or reflect those of the United States Government or any agency thereor. 
Chemical Technology Division

\title{
TREATMENT OPTIONS AND FLOWSHEETS FOR ORNL LOW-LEVEL LIQUID WASTE SUPERNATE
}

\author{
D. O. Campbell \\ D. D. Lee
}

Date of Issue - December 1991

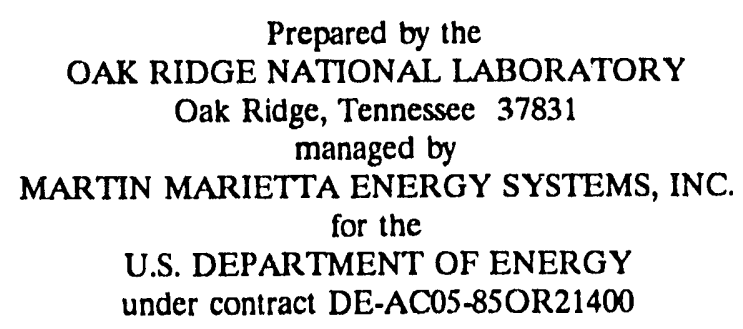




\section{CONTENTS}

LIST OF TABLES $\ldots \ldots \ldots \ldots \ldots \ldots \ldots \ldots \ldots \ldots \ldots \ldots \ldots \ldots \ldots$

LIST OF FIGURES $\ldots \ldots \ldots \ldots \ldots \ldots \ldots \ldots \ldots \ldots \ldots \ldots \ldots$

ACRONYMS AND INITIALISMS $\ldots \ldots \ldots \ldots \ldots \ldots \ldots \ldots \ldots \ldots$ vii

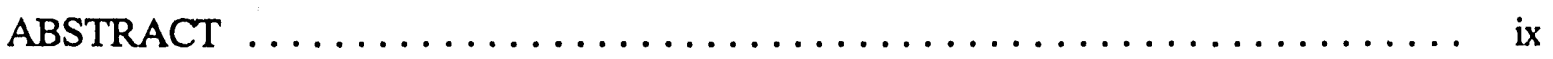

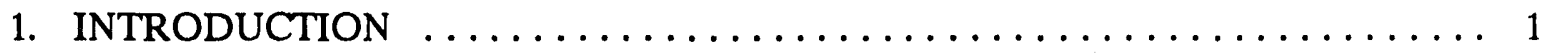

2. THE SCOPE OF THE PROBLEM $\ldots \ldots \ldots \ldots \ldots \ldots \ldots \ldots \ldots \ldots$

3. CHARACTERISTICS OF PROMISING TREATMENT PROCESSES $\ldots \ldots \ldots 7$

3.1 CESIUM DECONTAMINATION $\ldots \ldots \ldots \ldots \ldots \ldots \ldots \ldots \ldots \ldots \ldots$

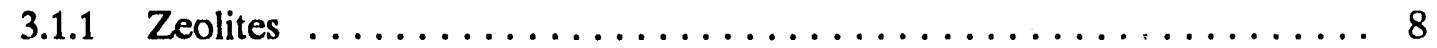

3.1.2 Organic Ion-Exchange Resins $\ldots \ldots \ldots \ldots \ldots \ldots \ldots \ldots \ldots \ldots \ldots \ldots \ldots \ldots$

3.1.3 Tetraphenyl Borate (TPB) .................... 9

3.1.4 Transition Metal Compounds with Hexacyanoferrate(II) (Ferrocyanides) 9

3.2 STRONTIUM DECONTAMINATION $\ldots \ldots \ldots \ldots \ldots \ldots \ldots \ldots \ldots \ldots$

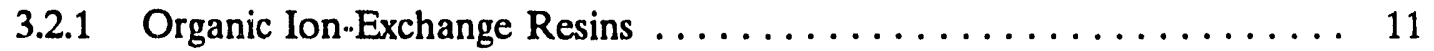

3.2.2 Inorganic Ion-Exchange Sorbents $\ldots \ldots \ldots \ldots \ldots \ldots \ldots \ldots$

4. PERFORMANCE OF SELECTED TREATMENT PROCESSES $\ldots \ldots \ldots \ldots \ldots 12$

4.1 PARAMETERS FOR MEASURING PERFORMANCE . . . . . . . . . . 12

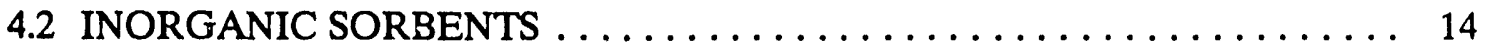

$4.2 .1 \quad$ Ferrocyanides . . . . . . . . . . . . . . . . . . . . . . 14

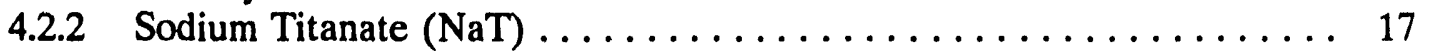

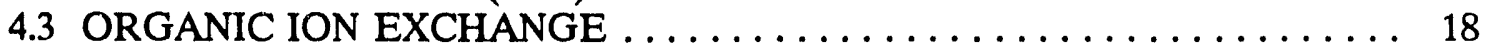

4.3.1 The SRS Resin .......................... 18

4.3.2 Chelating Resins . . . . . . . . . . . . . . . . . . . . . 19

5. PROCESS OPERATIONS AND FLOWSHEETS. $\ldots \ldots \ldots \ldots \ldots \ldots \ldots \ldots$

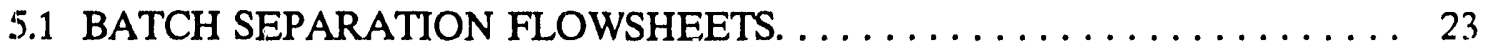

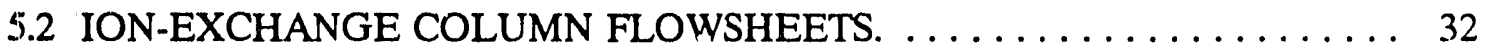

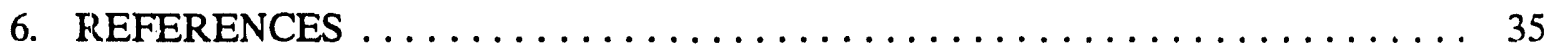

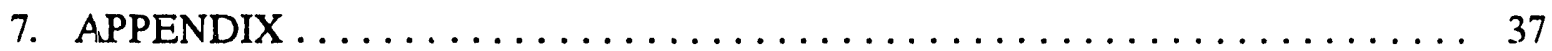




\section{LST OF TABLES}

Table $\quad \underline{\text { Page }}$

1. Maximum, minimum, and average radiochemical concentrations in the LLLW tanks 3

2. Maximum, minimum, and average chemical concentrations in the LLLW tanks . . 4

3. Required activity reduction factor to meet various standards $\ldots \ldots \ldots \ldots \ldots 6$

A-1. Calculated cesium removal in 1000-L one-stage mixer with successive $500 \mathrm{~L}$ feed batches ................................ 38

A-2. Calculated cesium removal in $1000-\mathrm{L}$ second-stage mixer with successive 500-L feed

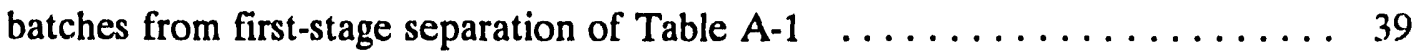

A-3. Calculated cesium removal following sorbent replacement in $1000-\mathrm{L}$ one-stage mixer with successive $500-\mathrm{L}$ feed batches

\section{LIST OF FIGURES}

Figure $\quad \underline{\text { Page }}$

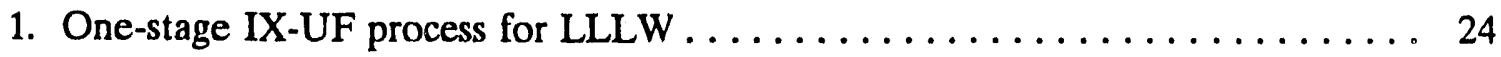

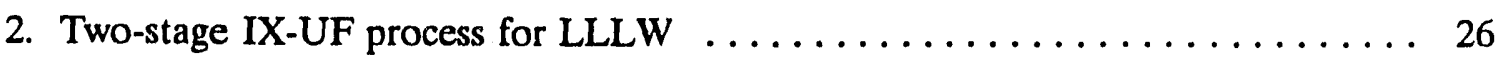

3. Supernate batch processing flowsheet (Alternate A) $\ldots \ldots \ldots \ldots \ldots \ldots 27$

4. Supernate batch processing flowsheet (Alternate B) $\ldots \ldots \ldots \ldots \ldots \ldots$

5. Near-term supernate treatment reference flowsheet $\ldots \ldots \ldots \ldots \ldots \ldots \ldots$

6. Supernate treatment with batch sorption and ion-exchange columns $\ldots \ldots \ldots 31$

7. Clarification-ion-exchange column flowsheet $\ldots \ldots \ldots \ldots \ldots \ldots \ldots \ldots$ 


\section{ACRONYMS AND INITIALISMS}

AMFC Nonstoichiometric compound of formula $A_{n} M_{(2-n / 2)} \mathrm{Fe}(C N)_{6}$ where $A$ is an alkali metal; $\mathrm{M}$ is a metal such as $\mathrm{Ni}, \mathrm{Co} \mathrm{Cu}$, or $\mathrm{Zn}$; and $\mathrm{FC}$ is ferrocyanide (i.e., NaNiFC for sodium nickel ferrocyanide

$\begin{array}{ll}\text { ARF } & \text { Activity reduction factor } \\ \text { CFR } & \text { Code of Federal Regulations } \\ \text { DF } & \text { Decontamination factor }\left(\mathrm{C}_{0} / \mathrm{C}\right) \\ \text { DOE } & \text { U. S. Department of Energy } \\ \text { FC } & \text { Transition metal hexacyanoferrate(II) compounds (feriocyanide) } \\ \text { IX } & \text { Ion-exchange processes } \\ \text { K } & \text { Distribution coefficient } \\ \text { LLLW } & \text { Low-level (radioactive) liquid waste } \\ \text { LLWDDD } & \text { Low-Level Waste Disposal, Development, and Demonstration Program } \\ \text { MVSTs } & \text { Melton Valley storage tanks } \\ \text { NaT } & \text { Sodium titanate } \\ \text { NRC } & \text { Nuclear Regulatory Commission } \\ \text { ORNL } & \text { Oak Ridge National Laboratory } \\ \text { SRS } & \text { Savannah River Site, DOE } \\ \text { TPB } & \text { Tetraphenyl borate } \\ \text { TOC } & \text { Total organic carbon } \\ \text { TRU } & \text { Transuranic } \\ \text { UK } & \text { United Kingdom }\end{array}$




\begin{abstract}
The properties of several chemical separations processes for removing cesium and strontium from high-salt low-level liquid waste (LLLW) supernate solutions are described. Both batch separations using highly selective inorganic ion-exchange materials and column processes using less-selective organic ion-exchange resins are feasible. These processes can be combined in different ways to give a variety of flowsheets for decontaminating the LLLW, and several possible flowsheets are described. The decontamination requirements depend on the LLLW composition and the specifications for the final waste forms after processing. Since several different waste forms might be acceptable, a wide range of requirements must be considered.

Moderate decontamination factors (DFs), in the range of 100 per separation stage for cesium and somewhat less for strontium, can be achieved by simple batch separations using a reasonable amount of sorbent. Larger DFs can be achieved with flowsheets using two or three stages in series, but at the expense of operational complexity. Simpler operation results if enough sorbent is applied to treat several batches of LLLW and the multiple batches are processed with that same sorbent before it is replaced. Moreover, it is not necessary to quantitatively remove the loaded sorbent from the treatment vessel when it is replaced with new sorbent. High DFs require unusually complete removal of the solid sorbent from the decontaminated solution, so solution clarification is a parallel problem.

Maximum DFs can be achieved with organic ion-exchange resins used in columns; but the resins are less selective, so more solid waste (spent resin) is generated. Combination flowsheets using both methods- a simple, one-stage batch process for the initial decontamination followed by polishing with a column - may be advantageous if large DFs are required because the high radiation levels occur in the batch process, which is relatively simple, and the more complex column operations will be concerned only with low radiation levels.

Flowsheets can be devised that appear capable of achieving very high decontamination of the bulk waste solutions with respect to ${ }^{137} \mathrm{Cs}$ and ${ }^{90} \mathrm{Sr}$, with DFs up to the order of $10^{6}$ or more. The volume of new solid waste concentrate generated (sorbents and resins) varies considerably, depending on the separation process used and the flowsheet, but may be in the range of $<0.1 \%$ of the LLLW volume for inorganic sorbents to perhaps $1 \%$ for organic resins.
\end{abstract}




\title{
TREATMENT OPTIONS AND FLOWSHEETS FOR ORNL LOW LEVEL LIQUID WASTE SUPERNATE
}

\author{
D. O. Campbell and D. D. Lee
}

\section{INTRODUCTION}

Low-level liquid waste (LLLW) is currently contained in ten 50,000-gal storage and process tanks at Oak Ridge National Laboratory (ORNL) and as residual heels in a number of older tanks that are no longer in active use. Plans are being formulated to treat these wastes, along with similar LLLW that will be generated in the future, to yield decontaminated effluents that can be disposed of and stable solid waste forms that can be permanently stored. The primary purpose of this report is to summarize the performance of the most promising separations processes that are appropriate for treatment of the LLLW supernate solution to remove the two dominant radionuclides, ${ }^{137} \mathrm{Cs}$ and ${ }^{90} \mathrm{Sr}$; to indicate how they can be integrated into an effective flowsheet; and to estimate the expected performance of such flowsheets in comparison to waste treatment requirements.

In general, an LLLW treatment process yields at least two products, a small concentrate containing nearly all the radioactivity and the decontaminated bulk material. A major cost factor, in addition to that for processing, is determined by the requirements for management, storage, and disposal of these products. Depending on disposal criteria, several combinations of product compositions might be acceptable; and several combinations of process steps and different modes of process operation can yield a specified product. Therefore, a number of different flowsheets might be practical, and a choice among them will be based on many factors. Technical considerations must be traded off against a variety of other, more or less arbitrary, constraints.

This study depends heavily on several reports published recently that also reference earlier work. The most important of these are the analytical data for the contents of the eight Melton Valley storage tanks (MVSTs) and the two tanks associated with the LLLW evaporator, ${ }^{1}$ the comparison of the LLLW tank compositions to a variety of waste criteria or disposal and storage of liquid and solid wastes, ${ }^{2}$ and the results of process development studies carried out with simulated and actual MVST wastes. ${ }^{23}$ 


\section{THE SCOPE OF THE PROBLEM}

Recent characterization studies have provided a data base for the contents of the eight MVSTs and two tanks associated with the LLLW evaporator, ${ }^{1}$ including estimates for both the sludge and supernate in each tank. The estimated combined volume for all ten tanks is $977 \mathrm{~m}^{3}$ (258,000 gal) of supernate plus $413 \mathrm{~m}^{3}$ (109,000 gal) of sludge. In addition to the measured supernate volume, the sludge contains in the vicinity of $342 \mathrm{~m}^{3}$ (90,000 gal) of interstitial solution (more or less similar to supernate), which might be processed in combination with the insolubles, or might be separated by washing from the true insolubles and then processed with the supernate. These data provide an estimate of the total amount of the species in each tank. ${ }^{2}$

From these volume estimates and the length of time allowed for processing, the average throughput rate can be estimated. For example, if $977 \mathrm{~m}^{3}$ (258,000 gal) of supernate is to be processed in 10 years, with 200 operating days per year, the average processing rate would be $490 \mathrm{~L} / \mathrm{d}(129 \mathrm{gal} / \mathrm{d})$. This is more in the bench scale to pilot-plant scale than the plant scale. However, it is anticipated that, over the time frame before the processing is complete, the total volume to be processed will be substantially increased (perhaps doubled) because of addition of LLLW currently existing in other (inactive) tanks and newly generated waste. Even considering such future additions, the required processing rate is relatively small. A scale in the vicinity of $1 \mathrm{~L} / \mathrm{min}(1440 \mathrm{~L} / \mathrm{d})$ appears appropriate.

The different tanks contain waste of substantially different compositions, and it is unlikely that they will be mixed into a reasonably uniform and average feed. There will certainly be additions to different tanks, probably containing higher conceritrations of radioactivity in some cases; and there will be transfers between tanks. Thus, the certainty is that compositions will be different than they are now, and they will vary with time during processing, depending on the exact source of the waste being processed. The current ranges of concentrations of important species show a variation of a factor of 10 or more for all important species except sodium, nitrate, and chloride (Tables 1 and 2 ). ${ }^{2} \mathrm{~A}$ head-end operation to bring the process feed to a specified composition range (i.e., $\mathrm{pH}$ ) will almost certainly be necessary.

The other essential data needed for identifying process requirements are the composition specifications for the products from the waste treatment process.

Unfortunately, these have not yet been defined completely. However, the specifications or acceptance criteria for various solid waste forms (such as NRC Classes A, B, and C and 
Table 1. Maximum, minimum, and average radiochemical concentrations in the LLLW tanks

\begin{tabular}{|c|c|c|c|c|c|c|}
\hline \multirow[b]{2}{*}{ Isotope } & \multicolumn{3}{|c|}{ Supernate $(\mathrm{nCl} / \mathrm{L})$} & \multicolumn{3}{|c|}{ Sludge $\left(\mathrm{nC}_{1} / \mathrm{L}\right)$} \\
\hline & $\operatorname{Max}$. & Min. & Avg. & Max. & Min & Avg, \\
\hline \multicolumn{7}{|c|}{ inalyses of MVSTs } \\
\hline H-3 & $1.67 E+04$ & $3.21 E+04$ & $7.16 \mathrm{E}+03$ & N.D. ${ }^{a}$ & & \\
\hline$c-14$ & $2.12 E+04$ & $2.70 E+01$ & $6.18 E+03$ & $2.87 E+04$ & $3.06 E+03$ & $7.85 E+03$ \\
\hline Co-60 & $3.29 E+05$ & $8.34 E+03$ & $1.03 E+05$ & $9.12 E+06$ & $2.76 E+05$ & $1.38 \mathrm{E}+r .6$ \\
\hline $\mathrm{Sr}-90$ & $4.73 E+06$ & $1.11 E+04$ & $1.48 E+06$ & $8,44 E+07$ & $1.55 E+07$ & $3.67 \mathrm{E}+07$ \\
\hline $\mathrm{Nb}-95$ & $7.56 E+03$ & $8.10 E+02$ & $2.90 E+03$ & $2.53 E+05$ & $1.91 E+04$ & $3.44 E+04$ \\
\hline $2 r-95$ & $1.92 E+05$ & $1.40 \mathrm{E}+03$ & $1.66 \mathrm{E}+04$ & $5.41 E+06$ & $5.78 E+04$ & $8.69 E+05$ \\
\hline$R u-106$ & $1.02 E+05$ & $2.97 E+04$ & $5.18 E+04$ & $2.24 E+06$ & $1.94 E+05$ & $3.67 E+05$ \\
\hline $\mathrm{Cs}-134$ & $3.54 E+05$ & $3.62 E+04$ & $1.49 E+05$ & $2.64 E+05$ & $2.11 E+04$ & $4.97 E+04$ \\
\hline$C s-137$ & $5.59 E+07$ & $5.08 E+06$ & $1.38 E+07$ & $2.84 E+07$ & $6.52 E+05$ & $8.51 E+06$ \\
\hline $\mathrm{C} \theta-144$ & $6.21 E+04$ & $2.00 E+04$ & $3.51 E+04$ & $1.06 E+06$ & 1. $33 E+05$ & $2.07 E+05$ \\
\hline Eu-152 & $8.84 E+05$ & $2.51 E+03$ & $6.67 E+04$ & $4.91 E+07$ & $5.78 \mathrm{E}+05$ & $5.75 E+06$ \\
\hline Eu-154 & $4.48 E+05$ & $1.62 E+03$ & $3.34 E+04$ & $1.86 \mathrm{E}+07$ & $1.99 E+05$ & $3.33 E+06$ \\
\hline Eu-155 & $1.41 E+05$ & $1.08 E+04$ & $2.59 E+04$ & $5.03 E+06$ & $2.72 E+04$ & 6. $97 E+05$ \\
\hline Gross alpha & $5.78 E+04$ & $2.70 E+01$ & $7.12 E+03$ & $8.15 E+06$ & $5.16 \mathrm{E}+05$ & $1.56 \mathrm{E}+06$ \\
\hline Gross beta & $5.94 E+07$ & $5.24 E+06$ & $1.75 E+07$ & $2.41 E+08$ & $4.90 E+07$ & $9.83 E+0 i$ \\
\hline$U-232$ & $1.84 E+03$ & $1.08 E+02$ & $2.28 \mathrm{E}+02$ & $5.97 E+04$ & $4.97 E+04$ & $6.36 E+03$ \\
\hline$U-233$ & $2.48 E+04$ & $1.62 E+02$ & $3.55 E+03$ & $4.27 E+05$ & $1.63 E+04$ & $6.29 E+04$ \\
\hline$U-235$ & N.D. & & & $1.06 \mathrm{E}+06$ & $1.26 E+05$ & $2.08 E+05$ \\
\hline$U-238$ & $2.70 E+02$ & $2.70 E+02$ & $2.70 E+02$ & N.D & & \\
\hline $\mathrm{Pu}-239 / \mathrm{Pu}-240$ & $1.67 E+03$ & $1.62 E+02$ & $1.38 E+02$ & $9.41 E+05$ & $2.99 E+04$ & $8.61 E+04$ \\
\hline $\mathrm{Pu}-238 / \mathrm{Am}-241$ & $7.05 E+03$ & $4.05 E+02$ & $5.01 E+02$ & $1.94 E+06$ & $8.27 E+04$ & $2.41 E+05$ \\
\hline $\mathrm{Cm}-243$ & N.D. & & & $9.45 E+05$ & $1.22 E+05$ & $2.05 E+05$ \\
\hline $\mathrm{Cm}-244$ & $3.11 E+04$ & $1.08 E+02$ & 1. $92 E+03$ & $6.04 \mathrm{E}+06$ & $1.36 E+05$ & $1.05 E+06$ \\
\hline
\end{tabular}

aN.D. = not determined in all tanks. 
Table 2. Maximum, minimum, and average chemical concentrations in the LLLW tanks

\begin{tabular}{|c|c|c|c|c|c|c|}
\hline & \multicolumn{3}{|c|}{ Supernate } & \multicolumn{3}{|c|}{ Sludge } \\
\hline & Max. & Min. & Avg. & $\operatorname{Max}$ & Min. & AvB. \\
\hline $\mathrm{pH}$ & 13.1 & 0.56 & 10.75 & & & \\
\hline Density & 1.29 & 1.20 & 1.23 & 1.54 & 1.26 & 1.35 \\
\hline Dissolved sollds, ms/mL & 485 & 348 & 386 & & & \\
\hline Total sollds, mg/mL & 478 & 334 & 386 & 544 & 369 & 470 \\
\hline Total carbon, $\mu_{B} / \mathrm{ml}^{2}$ & 9,500 & 364 & 1,340 & 22,200 & 1,820 & 10,800 \\
\hline Inorganio carbon, $\mu_{B} / \mathrm{ml}$ & 8,340 & 1 & 778 & 18,100 & 1,410 & 7,620 \\
\hline Organic carbon, $\mu \mathrm{g} / \mathrm{mL}$ & 1,285 & 167 & 565 & 6,480 & 410 & 3,330 \\
\hline Elemental analys is & $\begin{array}{l}\text { Max. } \\
(\operatorname{mol} / L)\end{array}$ & $\begin{array}{l}\text { Min. } \\
(\operatorname{mol} / \mathrm{L})\end{array}$ & $\begin{array}{l}\text { Avg. } \\
(\mathrm{mol} / \mathrm{L})\end{array}$ & $\begin{array}{l}\text { Max. } \\
(\operatorname{mol} 1 / \mathrm{L})\end{array}$ & $\begin{array}{l}\text { Min. } \\
(\operatorname{mol} / \mathrm{L})\end{array}$ & $\begin{array}{l}\text { Avg. } \\
(\mathrm{mol} / \mathrm{L})\end{array}$ \\
\hline Hydroxide & 0.29 & 0.01 & 0.082 & 0.29 & 0.01 & 0.082 \\
\hline Carbonate & & & & 2.02 & 0.15 & 0.85 \\
\hline Chloride & 0.14 & 0.06 & 0.085 & 0.14 & 0.06 & 0.085 \\
\hline Fluoride & 0.053 & 0.026 & 0.031 & 0.053 & 0.026 & 0.031 \\
\hline Nitrate & 5.97 & 3.23 & 4.38 & 5.97 & 3.23 & 4.38 \\
\hline Phosphate & 0.053 & 0.053 & 0.053 & 0.053 & 0.053 & 0.053 \\
\hline Sulfate & 0.081 & 0.052 & 0.055 & 0.081 & 0.052 & 0.055 \\
\hline Aluminum & $1.70 E-03$ & $4.45 E-05$ & $4.58 E-04$ & $4.28 E-01$ & $4.58 E-02$ & $1.57 E-01$ \\
\hline Arsenlc & $5.07 E-05$ & $4.00 E-05$ & $4.86 E-05$ & $1.34 E-03$ & $5.37 E-04$ & $7.72 E-04$ \\
\hline Barium & $1.82 E-04$ & $1.38 E-06$ & $3.21 E-05$ & $9.76 \mathrm{E}-04$ & $1.56 \mathrm{E}-04$ & $5.26 E-04$ \\
\hline Boron & $9.25 E-04$ & $1.85 \mathrm{E}-05$ & $1.72 E-04$ & $3.10 E-03$ & $1.40 E-04$ & $8.73 E-04$ \\
\hline Cadmium & $4.00 \mathrm{E}-05$ & $1.07 E-06$ & $8.48 E-06$ & $5.75 E-04$ & $1.91 E-05$ & $2.15 E-04$ \\
\hline Calclum & $5.74 E-01$ & $1.10 \mathrm{E}-04$ & $0.44 E-02$ & $2.00 E+00$ & $4.40 E-01$ & $2.50 E+00$ \\
\hline Chromiun & $5.19 E-04$ & $7.31 E-06$ & $9.37 E-05$ & $5.04 E-03$ & $6.54 \mathrm{E}-04$ & $2.42 E-03$ \\
\hline Cobalt & $9.67 E-06$ & N.D. & $5.80 \mathrm{E}-06$ & N.D. & & \\
\hline Iron & $4.30 E-03$ & $1.25 E-05$ & $4.68 \mathrm{E}-04$ & $6.34 E-02$ & $9.48 E-03$ & $3.30 E-02$ \\
\hline Lead & $3.43 E-05$ & $1.01 \mathrm{E}-05$ & $1.59 \mathrm{E}-05$ & $3.49 \mathrm{E}-03$ & $7.30 \mathrm{E}-04$ & $1.58 \mathrm{E}-03$ \\
\hline Magnesium & $2.30 \mathrm{E}-01$ & $5.35 E-05$ & $2.97 E-02$ & $9.19 E-01$ & $4.51 E-02$ & $4.62 \mathrm{E}-01$ \\
\hline Merci一y & $4.60 E-06$ & $2.30 \mathrm{E}-07$ & $8.48 E-07$ & $4.92 E-04$ & $6.92 E-05$ & $2.02 E-04$ \\
\hline Nickel & $2.55 E-04$ & $6.47 \mathrm{E}-06$ & $5.10 E-05$ & $2.51 E-03$ & $3.65 E-04$ & $1.15 \mathrm{E}-03$ \\
\hline Potassium & 1.99 & 0.22 & 0.615 & 0.62 & 0.20 & 0.36 \\
\hline Selenium & $5.85 E-05$ & $2.81 E-05$ & $5.34 E-05$ & $1.07 \mathrm{E}-03$ & $4.43 E-04$ & $7.63 \mathrm{E}-04$ \\
\hline S111con & $0.72 E-03$ & $3.56 E-05$ & $9.70 E-04$ & $3.60 E-02$ & $3.60 \mathrm{E}-03$ & $9.36 \mathrm{E}-03$ \\
\hline Silver & $1.11 \mathrm{E}-05$ & $4.08 E-06$ & $7.11 E-06$ & $6.49 E-04$ & $7.13 \mathrm{E}-05$ & $2.22 \mathrm{E}-04$ \\
\hline Soditum & 4.78 & 2.65 & 3.84 & 4.78 & 2.92 & 3.83 \\
\hline Strontium & $1.83 \mathrm{E}-03$ & $4.57 E-06$ & $3.24 E-04$ & $4.44 E-03$ & $4.31 E-04$ & $2.16 E-03$ \\
\hline Thallium & $6.85 E-06$ & $4.60 \mathrm{E}-06$ & $6.40 E-06$ & $1.28 \mathrm{E}-04$ & $6.56 E-0$. & $9.86 \mathrm{E}-05$ \\
\hline Thorium & $4.10 E-04$ & $4.31 E-06$ & $5.77 \mathrm{E}-0.5$ & $8.27 E-02$ & $8.04 E-03$ & $3.20 E-02$ \\
\hline Uranium & $4,75 \mathrm{E}-03$ & $4,20 \mathrm{E}-07$ & $8.05 E-04$ & $1.82 \mathrm{E}-01$ & $7,17 \mathrm{E}-03$ & 4. 39E-02 \\
\hline
\end{tabular}

${ }^{a}$ N.D. = none detected or not analyzed for. 
LLWDDD Class 1 and 2 limits) and liquid discharges (such as 10CFR20 App. B and DOE Order 5400.5) provide examples of the final compositions that might be acceptable under different constraints. These limits have been compared to the source term to provide an estimate of the activity reduction factor (ARF) required of the treatment process, if it is to meet various final waste requirements. These ARFs are summarized in Table $3 .^{2}$ At this point, one is in a position to evaluate processes for applicability and to consider how they might be integrated into a flowsheet.

The ARFs for discharge of liquid waste to the environment are quite large- in the range of $10^{6}$ to $10^{7}$ for ${ }^{90} \mathrm{Sr}$ and ${ }^{137} \mathrm{Cs}, 10^{6}$ for $\alpha$, and significant for several other radionuclides. There is uncertainty in interpretation of these requirements with regard to dilution that can occur when process streams are combined and treated; these dilution factors can be large. For solid wastes, NRC Class A requires a small DF for strontium and cesium $(<100)$, and Classes $A$ and $B$ both require a small $\alpha$ DF $(<10)$. The LLWDDD criteria for ORNL (presently under development and subject to revision) require large DFs for LLWDDD Class $1\left(10^{3}\right.$ to $10^{4}$ for ${ }^{137} \mathrm{Cs},{ }^{90} \mathrm{Sr},{ }^{60} \mathrm{Cc}$, and $\left.{ }^{152} \mathrm{Eu}\right)$, and $\alpha$ DFs of $10^{4}$ to $10^{5}$ for both LLWDDD Classes 1 and 2.

An optimal process will produce at least two wastes, and probably several of different characteristics. There will be a small-volume concentrate, which should be the solid waste form for disposal or storage, and one or more large-volume, decontaminated products containing the bulk of the physical material but very little radioactivity. There are a number of possible combinations of final waste forms that might be acceptable, so the ultimate decision will be based on several factors in addition to technical considerations. The concept underlying this work is that the volume of the waste forms containing the more hazardous constituents should be minimized, and the high-volume, bulk material should be decontaminated to the point that it can be disposed of or managed at significantly lower cost than the initial LLLW.

For example, the total quantities of the two dominant radioactive species $\left({ }^{137} \mathrm{Cs}\right.$ and ${ }^{90} \mathrm{Sr}$ ) in all the tanks combined are associated with $<1 \mathrm{~kg}$ of cesium and $\approx 27 \mathrm{~kg}$ of strontium. ${ }^{2}$ In contrast, there are $50,000 \mathrm{~kg}$ of $\mathrm{KNO}_{3}, 325,000 \mathrm{~kg}$ of $\mathrm{NaNO}_{3}$, and substantial amounts of other stable salts. Clearly, it is not a prudent use of limited radioactive waste disposal sites to fill them with some $400,000 \mathrm{~kg}$ of stable salts in order to dispose of $<30 \mathrm{~kg}$ of elements containing radionuclides. However, large amounts of nitrate are present, and some means of nitrate management may be required by 
Table 3. Required activity reduction factors to meet various standards

\begin{tabular}{|c|c|c|c|c|c|c|c|c|c|}
\hline $\begin{array}{l}\text { Waste type } \\
\text { and criteria } \\
\end{array}$ & Range & ${ }^{3} \mathrm{H}$ & ${ }^{14} \mathrm{C}$ & ${ }^{60} \mathrm{Co}$ & ${ }^{90} \mathrm{Sr}$ & ${ }^{106} \mathrm{Ru}$ & ${ }^{137} \mathrm{Cs}$ & ${ }^{152} \mathrm{Eu}$ & $\begin{array}{l}\text { Gross } \\
\text { alpha }\end{array}$ \\
\hline \multicolumn{10}{|l|}{ Liquid Wastes } \\
\hline \multirow[t]{3}{*}{ DOE 5400.5} & Max. & 8.3 & 304 & $6.6 \times 10^{4}$ & $4.7 \times 10^{6}$ & $1.7 \times 10^{4}$ & $1.9 \times 10^{7}$ & & $3.9 \times 10^{6}$ \\
\hline & Min. & 1.6 & $<1$ & $1.7 \times 10^{3}$ & $1.1 \times 10^{4}$ & $4.9 \times 10^{3}$ & $1.7 \times 10^{6}$ & & $1.8 \times 10^{3}$ \\
\hline & Avg. & 3.6 & 88 & $2.1 \times 10^{4}$ & $1.5 \times 10^{6}$ & $8.6 \times 10^{3}$ & $4.6 \times 10^{6}$ & & $4.7 \times 10^{5}$ \\
\hline \multicolumn{10}{|l|}{ Solid Wastes } \\
\hline \multirow[t]{3}{*}{ Class L-I } & Max. & 38.8 & $2.0 \times 10^{4}$ & $<1$ & $5.4 \times 10^{3}$ & & $7.7 \times 10^{4}$ & 86 & $1.2 \times 10^{S_{\mathrm{a}}}$ \\
\hline & Min. & 7.5 & 25 & $<1$ & 12.6 & & $7.0 \times 10^{3}$ & $<1$ & $324^{a}$ \\
\hline & Avg. & 16.6 & $5.8 \times 10^{3}$ & $<1$ & $1.7 \times 10^{3}$ & & $1.9 \times 10^{4}$ & 6.4 & $1.4 \times 10^{4 a}$ \\
\hline \multirow[t]{3}{*}{ Class L-II } & Max. & $<1$ & 106 & $<1$ & 2.1 & & $<1$ & $<1$ & $2.0 \times 10^{5 a}$ \\
\hline & Min. & $<1$ & $<1$ & $<1$ & $<1$ & & $<1$ & $<1$ & $92^{a}$ \\
\hline & Avg. & $<1$ & 31 & $<1$ & $<1$ & & $<1$ & $<1$ & $2.4 \times 10^{49}$ \\
\hline \multirow[t]{3}{*}{ NRC Class $A^{b}$} & Max. & $<1$ & $<1$ & $<1$ & 118 & & 55.9 & $<1$ & 1.2 \\
\hline & Min. & $<1$ & $<1$ & $<1$ & $<1$ & & 5.1 & $<1$ & $<1$ \\
\hline & Avg. & $<1$ & $<1$ & $<1$ & 37 & & 13.8 & $<1$ & $<1$ \\
\hline \multirow[t]{3}{*}{ NRC Class $B^{b}$} & Max. & $<1$ & $<1$ & $<1$ & $<1$ & & 1.3 & $<1$ & 8.9 \\
\hline & Min. & $<1$ & $<1$ & $<1$ & $<1$ & & $<1$ & $<1$ & $<1$ \\
\hline & Avg. & $<1$ & $<1$ & $<1$ & $<1$ & & $<1$ & $<1$ & $<1$ \\
\hline
\end{tabular}

NRC Class $C^{b}$ No DF is required to meet NRC Class $C$ requirements

${ }^{a}$ Gross alpha is assumed tc be ${ }^{239} \mathrm{Pu}$, the most restricted alpha emitter for Classes L-I and L-II.

bNRC limits are not presently applicable to DOE facilities but are presented for comparison. 
regulations. The total amount of nitrate, although extremely large compared to the quantity of radioactive elements, corresponds to the normal annual agricultural application to $<4000$ acres of East Tennessee pasture land.

Laboratory research studies have provided sufficient information to yield a reasonable understanding of the performance of the most important operations required for a flowsheet to treat LLLW supernate. ${ }^{3,4}$ Several factors must be balanced in assembling these operations into a flowsheet, such as combining processes into a single step and the proper sequencing of process steps that cannot be combined. The purpose of this report is to define the process steps for removing the two dominant radionuclides, ${ }^{90} \mathrm{Sr}$ and ${ }^{137} \mathrm{Cs}$, and the way that their performance depends on conditions so that a favorable flowsheet can be derived.

It is recognized that other materials may also have to be removed, depending on the final waste forms selected; these may include radionuclides such as actinides, ${ }^{60} \mathrm{Co}$, and ${ }^{14} \mathrm{C}$, as well as stable materials such as nitrates and toxic metals. The performance of different flowsheets can then be estimated and compared to the requirements based on disposal criteria for different waste forms. Depending on the final waste forms selected, required ARFs may range from none for some solid wastes to the order of $10^{7}$ for environmental release. $^{2}$ Thus, a wide range of flowsheet capabilities should be examined.

\section{CHARACTERISTICS OF PROMISING TREATMENT PROCESSES}

Several processes have been reported in the literature for separatinf, cesium and strontium from aqueous salt solutions, and some of them have been used in large-scale processing. The general characteristics of the more useful processes have been referenced in earlier reports ${ }^{3,4}$ and are summarized in this section.

\subsection{CESIUM DECONTAMINATION}

Several processes have been used for removing cesium from a variety of solutions at many different nuclear sites. Those that have been used successfully in operations of substantial scale include certain zeolites (chabazite, mordenite, etc.), phenolic ion-exchange resins (Duolite CS-100), tetraphenyl borate, and several transition metal hexacyanoferrate(II) compounds (ferrocyanide, abbreviated FC hereafter). All of these are subject to specific interferences with the MVST solutions, but the FC is less affected than the others. In general, the cesium removal problem is controlled by competition from other alkali metals, most importantly potassium, which is present in rather high concentration in 
some MVSTs. Thus, the method must be selective for cesium in competition with the very high sodium and moderately high potassium concentrations (Table 2).

\subsubsection{Zeolites}

Zeolites have been used to remove cesium from solutions of low to moderate salt concentrations and on a large scale in the case of fuel storage pool water. Although they are very effective for decontaminating water of low salt concentration (such as fuel storage pool water and groundwater), they are not sufficiently selective for cesium over sodium and potassium for practical application with MVST waste. Zeolites are being used to treat the high-level waste concentrate from the former Nuclear Fuel Services West Valley site (high $\mathrm{NaNO}_{3}$ but low $\mathrm{KNO}_{3}$ ), but generally $<100$ bed volumes can be loaded on a zeolite column. The loaded zeolites will be converted to glass. Since the waste volume is moderately small, the volume of vitrified waste can be tolerated.

In the MVST waste, the $\mathrm{NaNO}_{3}$ concentration is $\approx 4.5 \underline{\mathrm{M}}$, and the $\mathrm{KNO}_{3}$ concentration varies from $\approx 0.25 \underline{\mathrm{M}}$ in some tanks to $>1 \underline{\mathrm{M}}$ in two tanks. Under these conditions, the amount of zeolite required to decontaminate the solutions is large, probably $>2 \%$ of the volume of waste treated. Thus, a large volume of solid waste would be generated.

Regeneration of zeolites is not practical, so a multiple-cycle process to concentrate the cesium could not be used. Zeolites might have application for a final concentration step, and as the solid waste form, following a first-stage process using an organic ion-exchange resin. However, only limited scouting tests were made with zeolites, and they were not further considered for this problem.

\subsubsection{Organic Ion-Exchange Kesins}

In most cases, organic ion exchangers are relatively nonselective for separating cesium from sodium and potassium; but there are a few exceptions. Certain resins containing aromatic hydroxide groups (such as resins based on phenolic-formaldehyde polymers) are highly selective for cesium over sodium, but much less selective over potassium. A serious shortcoming of these resins is their instability to nitric acid above $\approx 0.5 \underline{\mathrm{M}}$ concentration. As result, elution requires large volumes of dilute nitric acid or more favorable volumes of nonoxidizing acids (such as $\mathrm{HCl}$ or $\mathrm{H}_{2} \mathrm{SO}_{4}$ ), which cause other problems in subsequent processing steps.

Duolite CS-100 is a resin of this type that has been commercially available, but now it is generally made on a special order basis. It was applied to treat ORNL LLLW many years 
ago and has also been used to treat LLLW at West Valley. It contains carboxylic exchange groups as well as the phenolic; and the carboxylic groups will remove strontium. Thus, this resin can remove both cesium and strontium. The problem is that, under most conditions, the capacities for the two elements are different; so whichever one breaks through first limits the column capacity. CS-100 resin was selected for further study by measuring both the static distribution coefficient $\left(\mathrm{K}_{d}\right)$ and dynamic column breakthrough curves under conditions representing the MVST supernate composition and dilutions thereof over a range of $\mathrm{pH}^{3,4}$

During the course of a waste treatment development program at the Savannah River Site, a new resin was developed that was somewhat related to CS-100 but is superior for cesium removal. ${ }^{5,6}$ The composition chosen for production on a demonstration scale is a polymer based on resorcinol rather than phenol, and it does not contain appreciable amounts of carboxylate. Thus, it is selective for cesium, but not very useful for strontium. Approximately $1 \mathrm{~L}$ of this resin (hereafter referred to as SRS resin ) was provided by R. M. Wallace of Savannah River for our developmental studies. This resin is being used in tests similar to those for CS-100 resin.,

\subsubsection{Tetraphenyl Borate (TPB)}

Tetraphenyl borate will be used to remove ${ }^{137} \mathrm{Cs}$ from high-level liquid waste at Savannah River, ${ }^{7}$ and a large-scale test was run successfully several years ago. Cesium tetraphenyl borate is insoluble, and cesium removal can be estimated by a solubility product relationship. Unfortunately, potassium and ammonium tetraphenyl borates are also insoluble, so they interfere seriously with cesium removal, such that enough reagent must be used to precipitate the potassium and ammonium ion, as well as the cesium. Since several of the MVSTs contain high potassium concentrations, this approach is not attractive for the ORNL LLLW. An additional problem with TPB is the production of aromatic hydrocarbons (primarily benzene) when it is hydrolyzed or decomposed in subsequent steps. Recovery and cisposal of these organic compounds would present a serious problem. This approach was not further investigated for the MVST waste.

\subsubsection{Transition Metal Compounds with Hexacyanoferrate(II) (Ferrocyanides)}

Ferrocyanides (FCs) have been studied extensively for cesium removal for many years. Although some early work was done at Savannah River, ${ }^{8}$ they have been used for removing cesium from various wastes mainly in Europe, notably in France. Active research and development programs also exist in the United Kingdom (UK) ${ }^{9 \cdot 11}$ and Finland ${ }^{12}$ as well as in 
other countries. A number of these compounds are quite insoluble over a wide $\mathrm{pH}$ range and are ion exchangers with an extremely high selectivity for cesium. There is an extensive literature covering a number of different formulations, but, for this application, the nickel and cobalt ferrocyanides appear most promising.

In general, these materials have the chemical formula $A_{n} M_{(2-n / 2)} F e(C N)_{6}$, where $A$ is an alkali metal (socium or potassium); $M$ is a metal such as nickel, cobalt, copper, or zinc; and $n<2$. Although apparently nonstoichiometric, they may be mixtures of compounds with $\mathrm{n}=0,1$, and 2. Alternatively, they more likely consist of a crystalline framework of the formula $\left[\mathrm{MFe}(\mathrm{CN})_{6}\right]^{2+}$, with the valence satisfied by the ions of $\mathrm{A}, \mathrm{M}$, or some other cation; these latter cations are exchangeable, with cesium being very strongly held. The actual composition depends on the detailed method of preparation and the composition of the solution in contact with the solid. These materials will be designated with the abbreviation AMFC in the following (i.e., NaNiFC for sodium nickel ferrocyanide) text. Some of these compounds are remarkably selective for cesium, so it is reasonable to achieve large DFs in simple one-stage batch mixing processes without having to use large amounts of sorbent. Batch processes, similar to common water treatment methods, may be much more practica! with these waste solutions than multistage column operations. This approach was selected for further study for application to the MVST supernate decontamination.

For the initial work on cesium removal, absorption on FCs was selected for the primary approach, and the SRS organic ion-exchange resin was chosen for the backup method. Both of these have been investigated under a range of reasonable conditions and have given promising results. ${ }^{3,4}$ It appears that either one or both in combination could be used for a decontamination flowsheet.

\subsection{STRONTIUM DECONTAMINATION}

Strontium removal may be limited by competition from either the very high alkali metal concentration in the MVSTs, or from the alkaline earth family, of which strontium is a member. Although several methods are reasunably selective for strontium over sodium, for example, the large excess of sodium (average $\mathrm{Na} / \mathrm{Sr}$ mole ratio in supernate $\sim 2 \times 10^{4}$ ) requires quite high selectivity. A more fundamental problem is presented by calcium and barium because it is generally much more difficult to separate strontium from these elements. Thus, the removal of strontium might require the simultaneous removal of at least most of the calcium, which is present in about 200 -fold excess in average supernate. The actual calcium concentration of the supernate varies greatly among the different tanks, 
and most of it is present in a few tanks at relatively low $\mathrm{pH}$. The situation is much worse in the sludge because it contains $>90 \%$ of all the alkaline earths.

Strontium removal presents two problems that must be considered. One is removal from sodium and potassium, or (approximately) the separation of alkaline earths from alkali metals. This can be done with many organic ion-exchange resins, most notably chelating resins, and with several inorganic ion exchangers. The other problem is the separation of strontium from the other alkaline earths, and particularly from calcium. There are laboratory methods under development for this, and a solvent extraction process using a crown ether offers promise; $;^{13}$ but no process is demonstrated. The required level of technology is much higher than that of waste management operations in general. Only the former separation (from alkali metals) is considered in this study, but sludge processing, to be advantageous, would probably require the separation of strontium from calcium as well.

\subsubsection{Organic Ion-Exchange Resins}

Organic resins will separate alkaline earths (and other polyvalent elements) from sodium and potassium, but the efficiency generally decreases as the competing salt concentration increases. The result is that, with the high-salt concentrations of MVST supernate, ion-exchange column breakthrough capacities tend to be fairly small. Since the resorcinolbased SRS resin is relatively ineffective for strontium removal from high-salt solutions, several chelating resins that are more selective for polyvalent metals were tested. These include IRC-718, Ionac SR-5, and Lewatit 207 and 208. They could be used either in a mixed bed with the SRS resin to remove cesium and strontium together, or in separate columns to remove them separately. These resins may also be useful for cobalt removal.

\subsubsection{Inorganic Ion-Exchange Sorbents}

Inorganic sorbents have been studied extensively, and several give efficient strontium separations from alkali metals even in high concentrations. These include materials such as hydrous zirconium oxide, hydrous titanium oxide, sodium titanate, polyantimonic acid, zirconium phosphate, and others. Several of these are available commercially in limited quantities and at high cost, while many have been used in laboratory studies only. Various forms of hydrous titania are available in larger quantities. Scouting tests were made with several materials that were available through other programs. The most promising was sodium titanate (NaT), which was developed for waste fixation during an extensive program at the Sandia National Laboratory several years ago. ${ }^{14}$ 
$\mathrm{NaT}$ was selected as the primary inorganic ion exchanger for strontium removal, and the organic chelating resins were chosen as the backup. Both of these have been investigated to a limited extent and have given promising results. ${ }^{3,4}$ However, further work is required.

\section{PERFORMANCE OF SELECTED TREATMENT PROCESSES}

Results from the experimental program have been reported $d^{3,4}$ and included in this section. The following decontamination methods appear most promising and have been studied for this problem.

Inorganic sorbents:

1. Cesium removal with $\mathrm{NaNiFC}$ or $\mathrm{KCOFC}$, and

2. Strontium removal with $\mathrm{NaT}$;

Organic ion-exchange resins:

3. Cesium removal with the SRS resin, and

4. Strontium removal with an organic chelating resin.

The inorganic sorbents generally are more selective than organic ion exchangers under reasonable conditions, and it is anticipated that they would give large DFs $\left(10^{2}\right.$ to $\left.10^{5}\right)$ if used in a batch (stirred-tank) mode consisting of one to three stages in series. This would be a relatively simple process rather like the sludge-precipitation processes commonly used in waste treatment. It must be recognized that solids in addition to the added sorbents may also be produced because of precipitation of constituents of the LLLW (i.e., from $\mathrm{pH}$ adjustment). The organic ion exchangers would be used in columns since their selectivity usually is not large enough for batch application, and they might be particularly suited for a polishing step to remove residual low levels of activity after the bulk had been removed by a batch process with the inorganic sorbents. Since a rather large column throughput would be advantageous, solids cannot be tolerated in column feed; so the solution would have to be carefully clarified.

\subsection{PARAMETERS FOR MEASURING PERFORMANCE}

Several parameters commonly used to describe the decontamination effectiveness can be related. All of the sorbents considered in the previous section, with the exception of TPB which follows a solubility product relationship, are ion exchangers; thus, they can be treated to a reasonable approximation in terms of the distribution coefficient, $K_{d}$, which is

$$
\mathrm{K}_{\mathrm{d}}=\left(\mathrm{C}_{0}-\mathrm{C}\right) \mathrm{V} / \mathrm{mC}=10^{6}\left(\mathrm{C}_{0}-\mathrm{C}\right) / \mathrm{C}(\mathrm{ppm}),
$$


where $\mathrm{C}_{0}$ and $\mathrm{C}$ are the aqueous concentrations (in any consistent units) before and after treatment, $\mathrm{m}$ is the mass of sorbent in $\mathrm{g}, \mathrm{V}$ is the volume of waste solution in $\mathrm{mL}$, and (ppm) is the amount of sorbent in parts per million, defined here as $\mathrm{mg}$ sorbent/L solution. A volumetric counterpart, $K_{d}{ }^{v}$, based on the volume of sorbent rather than the mass, is convenient for describing column performance because it is directly related to the throughput in column bed volumes. This is expressed as

$$
\mathrm{K}_{\mathrm{d}}{ }^{\mathrm{V}}=\left(\mathrm{C}_{0}-\mathrm{C}\right) \mathrm{V} / \mathrm{CV}_{\text {sorbent }}=\rho \mathrm{K}_{\mathrm{d}} \text {, }
$$

where $\rho$ is the tap density of the dry sorbent $(\mathrm{g} / \mathrm{mL})$.

The decontamination factor in this repoit is

$$
\mathrm{DF}=\mathrm{C}_{0} / \mathrm{C}=1+1 \times 10^{-6}(\mathrm{ppm}) \mathrm{K}_{\mathrm{d}} \text {. }
$$

Defined this way, the DF includes concentration reduction due to dilution during treatment, due to reagent addition, for example; as well as to ion exchange.

The reduction of activity (including dilution) can be expressed in percent as

$$
\% \text { removed }=100\left(\mathrm{C}_{0}-\mathrm{C}\right) / \mathrm{C}_{0}=100(1-1 / \mathrm{DF})=100(\mathrm{ppm}) \mathrm{K}_{\mathrm{d}} /\left[10^{6}+(\mathrm{ppm}) \mathrm{K}_{\mathrm{d}}\right] \text {. }
$$

In the data reported as DF or \% removed, the correction for changes in concentration because of the activity removed in successive samples taken at different times from a given experiment has not been made; but this was taken into account in calculating $\mathrm{K}_{\mathrm{d}}$. In effect, this causes the reported DF and \% removed to be slightly smaller than the true value in some cases.

For practical purposes, $K_{d}$ is directly related to the DF in a one-stage process, as shown above. If $K_{d}$ is large enough, reasonably large DFs (i.e., $~ 100$ ) might be obtained in one stage using a practical amount of sorbent (i.e., $<1000 \mathrm{ppm}=0.1 \mathrm{wt} \%$ ). If the system continues to obey the same equilibrium, the overall DF is squared if two batch separation stages are used in series, and cubed if three stages are used. Thus, reasonably large DFs can be achieved with a very few batch process stages if $K_{d}$ is large enough.

In the case of ion-exchange columns, the situation is different. Because a column normally has many separation stages, the column effluent will have a large DF initially, regardless of the value of $K_{d}$. However, the volume passed through the column before breakthrough occurs depends on $\mathrm{K}_{\mathrm{d}}$ and exchange kinetics. The midpoint of the breakthrough curve $\left(C / \mathrm{C}_{0}=0.5\right)$ occurs at a volume -proximately equal to $\mathrm{K}_{\mathrm{d}}{ }^{\mathrm{v}}$ bed volumes. The slope of the breakthrough curve is ru.uted to the ion-exchange kinetics. 
These two variables ( $\mathrm{K}_{d}{ }^{\mathrm{V}}$ and kinetics) together determine the throughput before intolerable losses would occur and therefore determine the effective column capacity. Depending on kinetics, the useful capacity may vary from somewhat less than $K_{d}{ }^{v}$ down to a small fraction of $K_{\gamma}{ }^{v}$, in units of bed volumes. Best results with columns are achieved if $K_{d}{ }^{v}$ is fairly large, a few thousand or more, and kinetic factors are favorable. If $\mathrm{K}_{\mathrm{d}}{ }^{v}$ is much larger, it is usually not possible to take advantage of the potentially very large column throughput because physical factors (such as plugging or fouling of the column due to solids) limit the capacity.

Such considerations suggest that one to three batch separation stages should be adequate for cesium and strontium decontamination using FCs and $\mathrm{NaT}$, respectively, which give very large $K_{d} s, 10^{5}$ to $10^{6}$, or even more under favorable conditions. On the other hand, the organic resins give $K_{d}{ }^{v} s$ in the range of $10^{2}$ to $10^{4}$, so that ion-exchange column operations are more suitable in general. Very different flowsheets can be made to work, and many factors such as equipment and space requirements, operational mode, and maintenance can be quite different. The selection of the optimum method or combination of methods will depend on the particular situation.

The general performance of these sorbents, with respect to flowsheet considerations, is discussed in this section.

\subsection{INORGANIC SORBENTS}

\subsubsection{Ferrocyanides}

The transition metal ferrocyanides are easily prepared as slurries by mixing a solution of $\mathrm{Na}_{4} \mathrm{Fe}(\mathrm{CN})_{6}$ or $\mathrm{K}_{4} \mathrm{Fe}(\mathrm{CN})_{6}$ with a solution of the metal salt (nickel or cobalt nitrate, chloride, or sulfate), and the slurry can be added to the waste solution after $\mathrm{pH}$ adjustment. ${ }^{3,4}$ They can also be precipitated in the waste solution by adding the reagents separately. The preferred ratio of metal to ferrocyanide is generally in the range of 1.5 to 1.7 , and a small fraction of the metal may precipitate as $\mathrm{Ni}(\mathrm{OH})_{2}$ or $\mathrm{Co}(\mathrm{OH})_{2}$, which strongly affects the sedimentation properties. If the mole ratio is $<1.5$, the slurries become more difficult to clarify. Precipitate particle sizes are very small at best. In some cases, the FC precipitate can be washed and dried to yield a hard product that can be broken into fragments suitable for column use; this is readily done with $\mathrm{KCOFC}$, but not with $\mathrm{NaCoFC}$, $\mathrm{KNiFC}$, or NaNiFC. The latter group can be prepared in granular form only by a long and tedious process. 
These sorbents may be used for cesium removal over the $\mathrm{pH}$ range from a maximum of about 11 down to moderately acidic solutions. The range 7 to 11 is of interest for this task, but decontamination of acidic solutions could be useful for treatment of specific wastes at the source. Above pH 11, the compounds are increasingly decomposed and lose effectiveness; thus, at higher $\mathrm{pH}$, higher AMFC concentrations are necessary. Experimental data indicate that $\approx 10 \mathrm{ppm}$ of NaNiFC is required with LLLW at $\mathrm{pH} 10$, and somewhat more at $\mathrm{pH} 11.4$ This loss of effectiveness at high $\mathrm{pH}$ occurs rapidly with powders, but granular $\mathrm{KCoFC}$ after proper conditioning is relatively stable for several days up to $\mathrm{pH}$ 13. Digestion at high $\mathrm{pH}(>13)$ eventually frees the cesium and ferrocyanide ion, leaving a nickel or cobalt hydroxide precipitate; in this way, the cesium could be recovered for further concentration, if desired.

Since the FCs are not stoichiometric, the actual concentration used is subject to some uncertainty. In this study, concentrations (as ppm, defined as $\mathrm{mg}$ solid/L solution) are calculated assuming all the metal ( $\mathrm{Ni}$ or $\mathrm{Co}$ ) and all the $\mathrm{Fe}(\mathrm{CN})_{6}{ }^{4 \cdot}$ form a precipitate, and, in addition, enough of the alkali metal ( $\mathrm{Na}$ or $\mathrm{K}$ ) is included to satisfy valency requirements. In practice, these sorbents do have a slight solubility, and a small fraction of the metal may be present as hydroxide rather than the compound, which would decrease the concentration. However, they are known to be hydrates, which would increase their mass. Most work was carried out with a nominal $100 \mathrm{ppm}$ by adding a prepared slurry corresponding to $5.7 \times 10^{-4} \underline{\mathrm{M}} \mathrm{Co}$ or $\mathrm{Ni}$ and $3.4 \times 10^{-4} \underline{\mathrm{M}} \mathrm{Fe}(\mathrm{CN})_{6}^{4}$, which calculates to be 104 and 108 ppm for the $\mathrm{Na}$ and $\mathrm{K}$ compounds, respectively.

Under these conditions, the exchange of cesium can be treated by the distribution coefficient concept, although $\mathrm{K}_{d}$ may not be exactly constant if the amount of exchanger is varied very far from $100 \mathrm{ppm}$. At very low sorbent concentrations, smaller $\mathrm{K}_{\mathrm{d}} \mathrm{s}$ may be observed, probably because of the small solubility of the exchanger and competition from trace elements in the solution. The values of $K_{d}$ are unusually large and remarkably insensitive to competition from high concentrations of sodium and potassium salts, typically being $1 \times 10^{6}$ or larger over the range up to $8 \underline{\mathrm{M}} \mathrm{NaNO}_{3}+1 \underline{\mathrm{M}} \mathrm{KNO}_{3}{ }^{4}$ Varying the cesium concentration up to $1 \times 10^{-5} \underline{\mathrm{M}}$ also had no major effect on $\mathrm{K}_{\mathrm{d}}$; the cesium concentration in the MVSTs is estimated to be $<5 \times 10^{-6} \mathrm{M}$. In general, NaNiFC appears to be somewhat superior to $\mathrm{KCOFC}$, especially at extremes of the ranges.

A performance estimate can be carried out on the basis of $100 \mathrm{ppm}$ sorbent with a $\mathrm{K}_{\mathrm{d}}$ of $1 \times 10^{6}$. With a one-stage batch separation under these conditions, the calculated DF is 101 and $99.0 \%$ of the $\mathrm{Cs}$ is removed. In many measurements, larger $\mathrm{K}_{\mathrm{d}} \mathrm{s}$ are often 
observed, up to $1 \times 10^{7}$, and the value is often limited by the extent of clarification. Thus, even with infinite $\mathrm{K}_{d}$, if $1 \%$ of the sorbent is not removed during clarification, $\mathrm{C}$ would be $\mathrm{C}_{0} / 106$ ) and the apparent $\mathrm{K}_{\mathrm{d}}$ would be $1 \times 10^{6}$. In many experiments, it has been possible to obtain apparent $\mathrm{K}_{d} \mathrm{~s}$ of $1 \times 10^{6}$ by simple filtration or centrifugation, and $\approx 1 \times 10^{7}$ by using a second clarification step of filtration or centrifugation. Sedimentation experiments give highly varied results, with a $\mathrm{K}_{d}$ of $\approx 2 \times 10^{5}$ (DF $\approx 20$ ) being typical after $20 \mathrm{~h}$ of settling on a 1-L scale with actual MVST supernate. After longer times, or particularly if the supernate is removed and allowed to settle another day, the $K_{d}$ is $\approx 1 \times 10^{6}$. Settling characteristics are known to depend on several conditions of the preparation procedure, such as the concentrations of reagents, mole ratios, order of addition, temperature, aging time, and others; and no prediction can be made other than by following a standard recipe. The use of surfactants might significantly improve clarification by sedimentation, but none has been investigated.

The FCs present a problem with respect to final disposition. It is possible to recover the cesium from them by treatment with $\mathrm{NaOH}$; but this is likely to evolve into a fairly complicated recycle scheme. The cesium could then be loaded on a stable solid such as a zeolite and incorporated into a solid waste form (concrete or glass). The FCs are suitable for direct fixation in certain wastes, such as concrete, and this has been investigated in the $\mathrm{UK}^{15}$ Cesium leach rates are low, and the waste is stable. As long as water is present, the temperature is necessarily limited and the compounds are sufficiently diluted by the concrete that they are stable. However, a serious potential problem has developed recently at Hanford because very large quantities of FCs and mixtures of nitrate/nitrite salts have been dewatered in large storage tanks. ${ }^{16}$ This situation is under intensive investigation currently, and the result will determine how FC wastes can be solidified.

If the FCs are dried and heated, they decompose, giving off toxic cyanogen gas among other compounds; this can be oxidized in air. If FCs are present in high concentration and heated with oxidants (such as $\mathrm{NaNO}_{3}$ ), a rapid exothermic chemical reaction can occur, leading to pressurization of the vessel and possibly an explosion, depending on conditions. This can be avoided by dilution with inert solids or by ensuring that the temperature is not excessively high, but it will probably be necessary to avoid the existence of mixtures of FC and oxidant (nitrate salts), except when excess water is present to guarantee an adequately low temperature. In any case, it will be required that proper attention be given to the method for disposing of FC wastes. 


\subsubsection{Sodium Titanate (NaT)}

Sodium titanate has been investigated to a lesser extent than the FCs, but the use of one particular material can be defined reasonably well. There are many different forms of $\mathrm{NaT}$ and sorbents based on hydrous titania. The material studied is a NaT prepared at the Sandia National Laboratory ${ }^{14}$ and formed into a granular product by Cerac Corporation during a development program several years ago; we obtained several hundred grams of the material at that time. There is good evidence that the NaT powder prepared originally by Sandia would be a better material for the batch contacting under consideration here, because it would suspend in the solution more readily and sorb strontium more quickly; in addition, it is expected to have a larger $K_{d}$ for strontium. $R$. Dosch, who originally developed the material, has been contacted and supplied a new sample for future testing. Sodium titanate will also be used for strontium removal at the Savannah River Site.

In addition, reagent grade $\mathrm{TiO}_{2}$ and several preparations microspheres of hydrous titania, NaT, titanium phosphate, and zirconium phosphate made by the internal gelation method have been used in scouting tests. ${ }^{4}$ All of these were considerably inferior to the $\mathrm{NaT}$, but it is possible that sol-gel material with better exchange properties could be prepared. The following discussion, however, is based on experiments with the granulated Sandia NaT material.

Strontium removal with NaT shows a large increase with increasing $\mathrm{pH}$, in contrast to Cs removal with FCs, which shows essentially no $\mathrm{pH}$ dependence up to $\mathrm{pH} 11$ and then a total loss of effectiveness as the $\mathrm{pH}$ increased above 11. At $\mathrm{pH} 13$ or higher, the strontium $\mathrm{K}_{\mathrm{d}}$ with $\mathrm{NaT}$ approaches $1 \times 10^{6}$. In the $\mathrm{pH}$ range $<11$, suitable for $\mathrm{FCs}, \mathrm{K}_{\mathrm{d}}$ is in the lowto-mid $1 \times 10^{4}$ range; thus, strontium removal is much less efficient in the $\mathrm{pH}$ range suitable for cesium removal than it is at a higher $\mathrm{pH}$. For example, in experiments with simulants with $455 \mathrm{ppm} \mathrm{NaT}$, the strontium DF was 7 at $\mathrm{pH} \mathrm{10,14}$ at $\mathrm{pH} \mathrm{11,25}$ at $\mathrm{pH} \mathrm{12}$, and 330 at $\mathrm{pH} 13.4$ Because the favorable $\mathrm{pH}$ range for the two processes (cesium and strontium removal) is different, both can not be utilized at optimum effectiveness with the same solution; this presents a flowsheet problem.

The most effective use of $\mathrm{NaT}$ for $\mathrm{Sr}$ removal occurs at high $\mathrm{pH}, 213$. It may be practical to include such a high-pH step in a flowsheet. Clarification at high $\mathrm{pH}$ may be desirable in any case, to minimize actinide (TRU) activity and remove some other metals. Tank sampling has demonstrated that many metals are concentrated in the sludge, with only a small fraction in the supernate. If a high-pH treatment is used, one option would be to combine the NaT process for strontium removal with this step. Another option is to add 
NaT to the MVSTs if they are operated at a $\mathrm{pH} \geq 13$. This would precipitate nearly all the strontium and maintain it in association with the sludge as long as the $\mathrm{pH}$ remained high. However, it is not clear that adequate mixing can be achieved in the MVSTs to ensure an effective process, and the solid would have to be recovered from the tanks eventually.

It would also be possible to use $\mathrm{NaT}$ in the cesium removal process with $\mathrm{FC}$, if a large strontium DF is not required. This could be carried out at $\mathrm{pH} 10.5-11$, even though strontium removal would not be very efficient under this condition. Possibly, a higher $\mathrm{pH}$ could be used with NaT and a stabilized $\mathrm{KCoFC}$, at about $\mathrm{pH} \mathrm{13;} \mathrm{but} \mathrm{there} \mathrm{would} \mathrm{be} \mathrm{a}$ time constraint on the contact time, and either cesium or strontium would not be permanently held by the sorbents (depending on whether the $\mathrm{pH}$ of the waste slurry subsequent to treatment was $>11$ ). Also, the stabilized $\mathrm{KCoFC}$ would be much more expensive to prepare.

The titanates cannot be effectively eluted, so they logically become the solid waste for disposition. Much work has been done relating to the incorporation of $\mathrm{NaT}$ in solid wastes. Strontium titanate has been used as an isotopic heat source material. It is stable, nonreactive, and suitable for incorporation in a variety of solid waste forms.

\subsection{ORGANIC ION EXCHANGE}

\subsubsection{The SRS Resin}

The resorcinol-based Savannah River resin is effective for cesium removal over a fairly wide $\mathrm{pH}$ range, but the optimum $\mathrm{pH}$ is $\approx 12.5$; as $\mathrm{pH}$ decreases, it gradually becomes less efficient. ${ }^{3,4}$ An important consideration with this resin is that potassium interferes to a significant extent, and the potassium concentration is high in some tanks. The potassium content is probably the largest factor mitigating against use of organic resins, versus FCs. Several tanks are $\sim 0.25 \underline{\mathrm{M}}$, but others are $>1 \underline{\mathrm{M}}$, and the average of all supernate is $0.51 \underline{\mathrm{M}}$ (and increasing, unfortunately). The capacity of an ion-exchange column, estimated from batch distribution data, is not more than 500 column volumes at $0.5 \underline{\mathrm{M}} \mathrm{K}^{+}$. Thus, treatment of all the current supernate would require $\approx 2000 \mathrm{~L}$ of resin on a once-through basis. This can be visualized as 100 runs through columns containing $20 \mathrm{~L}$ of resin or about 10 runs with columns the size of 55-gal drums. The effectiveness of this resin for strontium removal is much poorer, with the breakthrough estimated to occur at $\approx 100$ column volumes; thus, a different resin would be used for strontium (see next section).

There are two methods that might be considered. One is to use a few resin columns repeatedly, eluting the activity and regenerating the resin after each loading cycle, which is 
the way ion-exchange columns are usually operated. Unfortunately, this resin has been somewhat difficult to elute; ${ }^{4}$ so extensive equipment is required and large volumes of recycle streams are generated, adding to the total LLLW quantity. This class of resins is unstable to nitric acid except at low concentrations, so nitric acid elution generates a large volume of product. Hydrochloric acid is effective, but it presents a problem in material selection for the evaporator used to concentrate the product. Formic acid has been investigated, but it required large volumes for reasonably complete elution, also. Currently, there is no easy answer for this problem.

The second method is to use the resin on a once-through basis, with the loaded resin being the solid waste form. Since the organic resin may not be an acceptable waste, it right be necessary to burn or thermally decompose the resin, leaving a granular ash containing the radioactivity and other metals. This has been done on a modest scale for making irradiation targets ${ }^{17}$ and enriched uranium microspheres for reactor fuel elements; the particles were mixed with metal powders or carbon and pressed into solid pellets. This approach would require small equipment to treat the resin $(<10 \mathrm{~kg} / \mathrm{d})$, and would consume much more resin (up to $300 \mathrm{ft}^{3}$ ); but it would avoid the elution and regeneration of the resin columns and eliminate the need for the associated equipment for concentration and recycle. The cost of resin is probably minor compared to costs for equipment and operation.

\subsubsection{Chelating Resins}

Several chelating resins were tested for strontium removal. These included IRC-718, Ionac SR-5, and Lewatit 207 and 208, all of which were found to be quite effective, as well as the SRS resin and Duolite CS-100, which were less effective. Batch distribution tests do not allow an unambiguous choice because conditions such as the phase ratio (related to throughput of a column), contact time (related to flow rate), and $\mathrm{pH}$ all affected the results. However, IRC-718 and the two Lewatit resins showed excellent potential column capacities, in the vicinity of $2000-3000$ bed volumes, corresponding to $\approx 500 \mathrm{~L}$ of resin to treat all the current supernate. The final choice will depend on the specific conditions of application.

The chelating resin could be used either mixed with SRS resin for simultaneous removal of both cesium and strontium in the same column or in separate columns in series. The second approach is probably advantageous because conditions such as residence time during loading and the elution procedure could be optimized for each resin. A small-scale 
column test, made with a mixed bed of SRS resin and IRC-718 to remove both elements together, indicated a useful column capacity of $\approx 200$ bed volumes. This corresponds to $5000 \mathrm{~L}$ of the resin mixture to remove both cesium and strontium (or 100 runs with $50-\mathrm{L}$ columns), which is larger than the sum of the estimates from batch experiments with the individual resins. This is probably because of experimental variations, since small-scale ion-exchange columns often give conservative results.

Strontium can be eluted from the chelating resins with acids much more readily than can cesium be eluted from the SRS resin. Thus, elution does not present as much of a problem. The other option, burning or decomposing the resin for generation of a solid waste, is also possible, as described above.

\section{PROCESS OPERATIONS AND FLOWSHEETS}

Several operations are possible for removing actinides, cesium, and strontium from the waste, and the flowsheet will consist of a rational combination of these individual steps. The operations considered in this study are the following:

1. Clarification to remove insoluble species, notably actinides, ${ }^{60} \mathrm{Co}$, and other metals, from the supernate, either at $\mathrm{pH} \geq \sim 13$ or $\leq 11$;

2. Cesium removal by inorganic ion exchange with $\mathrm{FC}$ in a batch process, at $\mathrm{pH}<11$;

3. Cesium removal by organic ion exchange with the SRS resin in a column process, at pH 11 to 13 but preferably -12.5 ;

4. Strontium removal by inorganic ion exchange with $\mathrm{NaT}$ in a batch process, preferably at high $\mathrm{pH},>\sim 13$;

5. Strontium removal by organic ion exchange with a chelating resin, with $\mathrm{pH}$ 10-13.

Different processes have different optimum $\mathrm{pH}$ values, so it would be advantageous to operate different steps at two different pHs, such as 10.5-11 and 12.5-13. The lower pH range is necessary for cesium removal with $\mathrm{NaNiFC}$ and is satisfactory for strontium removal with chelating resins. The higher $\mathrm{pH}$ range is necessary for efficient strontium removal with $\mathrm{NaT}$ and for cesium removal with the SRS resin, and it is expected to be advantageous for alpha removal by clarification. There will probably be a problem from solids formation as $\mathrm{pH}$ is changed because several metals are at their solubility limit in the supernate solution; some are less soluble as $\mathrm{pH}$ is decreased (aluminum), and some are less soluble as $\mathrm{pH}$ is increased (calcium, magnesium). Such solids may seriously interfere with an ion-exchange column operation since the $\mathrm{pH}$ often changes within the column. 
Therefore, it is recommended that batch separations be used in the early stages when radioactivity levels are higher and that columns be used (if necessary) only after activity has been reduced so that hands-on maintenance is practical.

Clarification is probably most advantageous, with respect to alpha and cobalt decontamination, at the highest practical $\mathrm{pH}$; and a very efficient solids removal step is expected to be necessary to ensure adequate removal of alpha activity. However, a fairly high degree of clarification may be necessary between each batch separation stage so that solids carryover is not limiting, but rather ion exchange is. For example, under the conditions for batch separation of cesium discussed before, at least $99 \%$ removal is projected; thus, one would require at least $99 \%$ solids rejection in the clarification step following that operation. In very limited tests, sedimentation and decantation have not given that degree of solids separation unless settling times were in excess of $1 \mathrm{~d}$. It is possible that settling could be used for the first stage of decontamination, because it is a simple step that is unlikely to require maintenance; but it is expected that better separations will be obtained, overall, with filtration following subsequent batch separation stages.

Several clarification methods are possible, in principle, but filtration appears to be more suitable than centrifugation because of the low average throughput, the long operating time, and maintenance considerations. For this sort of process, in which solid sorbents are not being removed from the process but rather are being retained within a particular stage of a series of stages, cross-flow filtration appears to be well-suited. The nature of the filter element, such as pore size, remains to be determined from hot testing on a larger scale. It is known that both the FCs and titanates exist partly as very small (submicron) crystals, so it is expected that a very small pore size will be necessary, for example, $s 0.1 \mu \mathrm{m}$.

Ultrafiltration has been recommended in studies in the United Kingdom, using filters with a molecular weight cutoff of $\approx 10,000$ to 20,000 (corresponding to $\approx 0.003-\mu \mathrm{m}$ pore size). The same cross-flow concept, and even equipment (except for the filter membrane), can be used for both ultra- and conventional filtration.

One can propose a batch-processing flowsheet consisting of three separation stages (mixing tanks), with a filtration step following each:

\begin{tabular}{|c|c|c|c|c|c|}
\hline Stage 1 & & Stage 2 & & Stage 3 & \\
\hline $\begin{array}{l}\text { pH adjust } \\
\text { add sorbent } \\
\text { mix }\end{array}$ & $\rightarrow$ filter $\rightarrow$ & $\begin{array}{l}\mathrm{pH} \text { adjust } \\
\text { add sorbent } \\
\text { mix }\end{array}$ & $\rightarrow$ filter $\rightarrow$ & $\begin{array}{l}\text { add sorbent } \\
\text { mix }\end{array}$ & $\rightarrow$ filter $\rightarrow$ Product \\
\hline
\end{tabular}


If solids (sludge) are transported to the processing equipment with the supernate, it may be necessary to use the Stage 1 vessel only for feed adjustment and clarification, without the addition of a sorbent; the solids could be returned to the MVSTs or solidified as a TRU waste. The flowsheet could be operated in a simple batch mode or as a continuous or semicontinuous process with a relatively large volume flowing through the successive stages. The sorbents would be either removed and replaced periodically, or moved to the preceding stage instead of being replaced, to maintain the necessary DF. If greater decontamination is required, either additional batch stages or ion-exchange columns could be used, possibly reaching radioactivity levels low enough for environmental discharge. The solid sorbent is the waste concentrate, and the treated solution must be decontaminated adequately for its specified fate (direct solidification, further decontamination, or possibly discharge). These flowsheets are considered in Sect. 5.1.

One can also propose a process using ion-exchange columns rather than batch separation stages:

\begin{tabular}{ll}
$\mathrm{pH}$ adjust & $\rightarrow$ clarify $\rightarrow \begin{array}{l}\text { SRS resin } \\
\text { columns }\end{array} \rightarrow \begin{array}{l}\text { chelating } \\
\text { resin columns }\end{array} \rightarrow \rightarrow$ Product \\
\hline
\end{tabular}

Such columns readily give many equivalent separation stages, and their size is determined primarily by residence time requirements. The maximum throughput depends on conditions but should be in the range of a few hundred to a few thousand bed volumes. As noted in Sect. 4.1, this is related to $\mathrm{K}_{d}{ }^{v}$ and exchange kinetics. The amount of resin required is the volume to be processed divided by the throughput. A representative estimate is $2000 \mathrm{~kg}$ of SRS resin for cesium plus $500 \mathrm{~kg}$ of chelating resin for strontium (Sect. 4.3). This could be used on a once-through basis. Proportionately less resin could be used in multiple load/elute cycles, but that would lead to a major complication of operations since elution of the SRS resin has not been easily achieved. These flowsheets are considered in Sect. 5.2.

Combinations of the two approaches can also be used. The head-end step for the ion-exchange column process could easily involve a scavenging precipitation to aid the clarification operation, and an inorganic ion exchanger could be included as well. Without adequate pretreatment, it is anticipated that plugging of ion-exchange columns is likely because of precipitation of metal compounds within the columns, resulting in a much smaller column throughput than predicted. This would cause operation to be more difficult, the resin requirement to be larger, and the amount of waste concentrate generated to be greater. 


\subsection{BATCH SEPARATION FLOWSHEETS}

Batch separation processes that are sufficiently selective can be used to effectively accomplish some, and perhaps all, of the goals of this task. In general, the inorganic ion-exchange processes (FCs and NaT) are appropriate for this application. A simple onestage batch separation is indicated schematically in Fig. 1. This shows a mixing vessel and cross-flow filter to retain the sorbent in the vessel and clarify the product. As a model of such a one-stage batch process, $\mathrm{NaNiFC}$ at $104 \mathrm{ppm}$ with $\mathrm{K}_{\mathrm{d}}=10^{6}$ would give a DF of 105 , or $99 \%$ cesium removal. With respect to cesium, this would be adequate, for example, for solidification of the supernate as an NRC Class A solid waste. The sorbent would constitute $1.04 \mathrm{~kg}$ of solids per $10,000 \mathrm{~L}$ processed and contain an average of $13.6 \mathrm{Ci}$ of ${ }^{137} \mathrm{Cs}$.

If a substantially greater DF is required (as for the LLWDDD Class 1 or the liquid wastes), additional batch separation stages can be added in series. Under the same conditions (104 ppm with $\mathrm{K}_{\mathrm{d}}=10^{6}$ two stages would give a DF of $\approx 10^{4}$ (possibly adequate for LLWDDD Class 1 ) and three $\approx 10^{6}$ (nearly enough for liquid waste discharge). For most efficient use of the sorbent (which is advantageous because of its cost and the possible hazard provided by large quantities of FCs in the solid waste), after it is loaded it should be transferred between batch mixers in a direction countercurrent to the solution flow instead of being removed and replaced with new sorben'; of course, the final stage would require new sorbent.

The sorbents can be applied in different ways. If the amount of sorbent is increased, the DF increases roughly in proportion. For example, with $\mathrm{K}_{\mathrm{d}}=1 \times 10^{6}, 1040 \mathrm{ppm}$ would give a DF of $\approx 1000$ in a single contact, and $10,400 \mathrm{ppm}(1 \%)$ would give a DF of $\approx 10^{4}$. However, if two successive contacts are used, each with $104 \mathrm{ppm}$, the DF would be $\sim 10^{4}$, as noted above. For the cases with $\mathrm{DF} \approx 1 \times 10^{4}$, there would be $104 \mathrm{~kg}$ sorbent per $10,000 \mathrm{~L}$ of waste treated with a single contact and $2.1 \mathrm{~kg}$ sorbent per $10,000 \mathrm{~L}$ with two contacts in series. Thus, the use of two or three successive contacts requires much less sorbent for a given DF, thereby substantially reducing the cost of reagents and the amount of solid waste concentrate formed. The disadvantage is the additional equipment required, associated with two or three mixing tanks instead of one.

Because it is somewhat difficult to quantitatively remove the small amount of solid sorbent from the mixing vessel after each batch is processed, a simpler approach is to start with enough sorbent to treat several batches of supernate and then run proportionately more batches of waste solution through that separation stage. For example, if 10 times as 


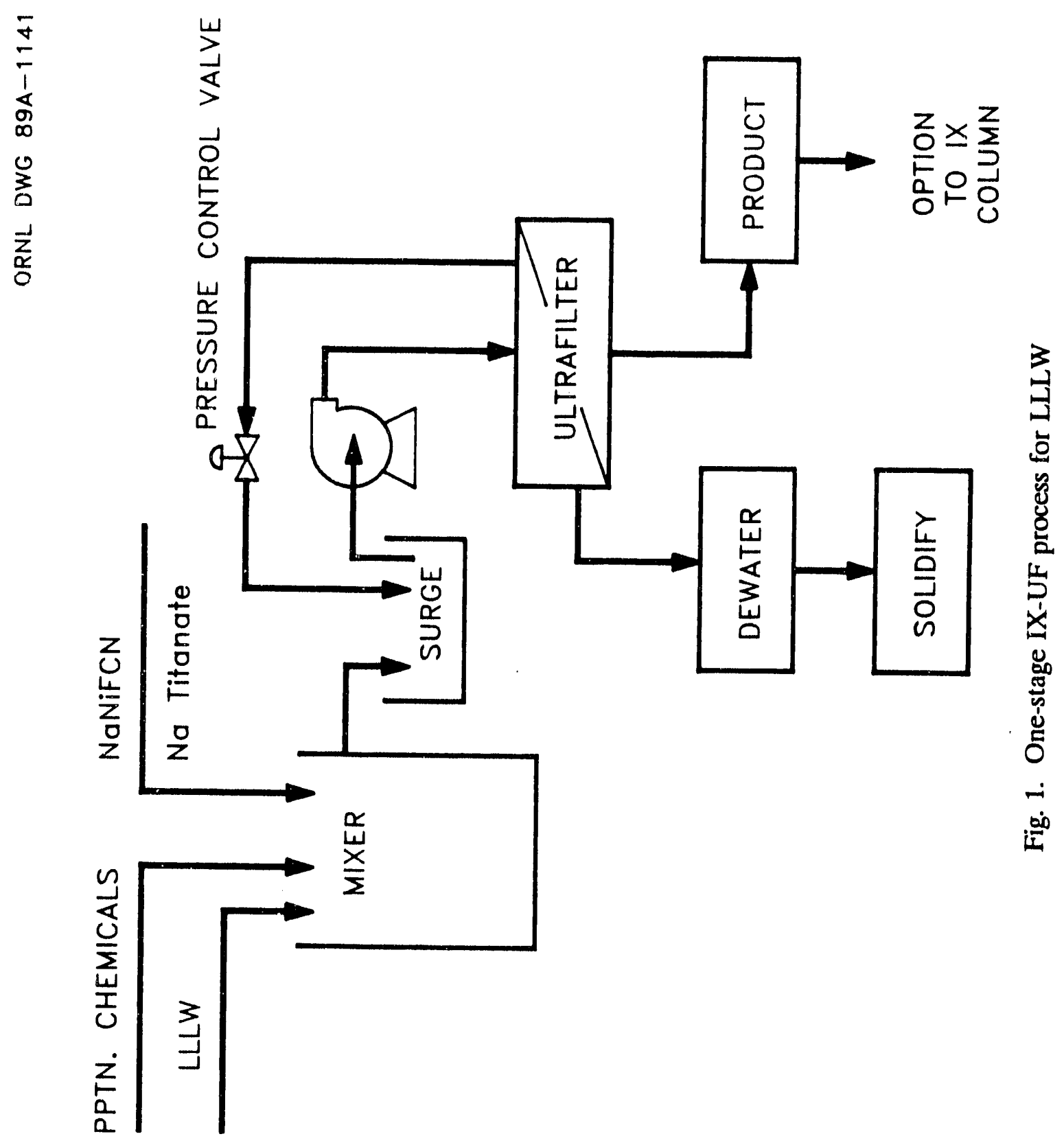


much sorbent (1040 ppm, based on the volume of the mixer or contacting vessel, or $1.04 \mathrm{~kg}$ in a $1000-\mathrm{L}$ mixer) is used in a single-stage mixer, and successive batches of solution are contacted, removed, and replaced without removing the sorbent, the calculated DFs are shown as a function of volume processed in Table A-1, both for successive batches and averaged for the total accumulated volume processed. In this case, the sorbent might be removed and replaced after 10,000 to $20,000 \mathrm{~L}$ are processed. This approach results in a greater average DF for a given volume processed and amount of sorbent used, compared to individual batches each at 104 ppm sorbent.

A modification of this scheme, consisting of a two-stage countercurrent process, is shown in Fig. 2. The first stage operates by sedimentation to avoid system complexity in the highest-activity part of the process, and the second stage uses a high-efficiency filter to produce a well-clarified product. The concentrate from the filter, containing sorbent, is cycled back to the first stage, where the loaded sorbent settles and is removed as sludge. It is expected that such a process, with $100 \mathrm{ppm} \mathrm{NaNiFC}$ in each mixing vessel, would give a cesium DF of $\approx 2000$, depending on sedimentation time in the first stage.

More conventional flowsheets, using head-end feed adjustment and clarification followed by two or three batch separation stages, are illustrated in Figs. 3 and 4. The flowsheets differ through the use of a filter between stages in Fig. 4 to ensure maximum effectiveness. In both cases, the first stage is a feed adjustment step that would be tailored to the particular waste process. For example, the $\mathrm{pH}$ could be adjusted to $\approx 13$ to minimize the solubility of uranium, other actinides, rare earths, cobalt, and other metals, and a polyelectrolyte is proposed to improve clarification properties. The solids could be solidified directly or returned to the MVSTs for storage and the supernate processed. Sodium titanate (to remove ${ }^{90} \mathrm{Sr}$ ) and other scavengers could also be added, if desired. Alternatively, the $\mathrm{pH}$ could be adjusted to $\sim 10.5$ and $\mathrm{NaNiFC}$ added to remove ${ }^{137} \mathrm{Cs}$; in this case, the solids should not be returned to the MVSTs. Such head-end steps would remove actinides and rare earths (europium may be present), any solids entrained in the supernate or produced by the feed adjustment, and any activity loaded on added sorbents.

Additional stages could be used in series, but all except the first stage would use only the ion-exchange sorbents. It is necessary to adjust the $\mathrm{pH}$ to $\approx 10.5$ for all stages using FC for cesium removal. The equipment up to and including the first ion-exchange stage would require substantial shielding, while the others would need good containment and light shielding. Calculated cesium DFs are shown in Table A-2 for the second stage of a twostage process, for which Table A-1 represents the first stage. 


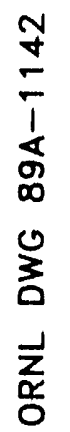

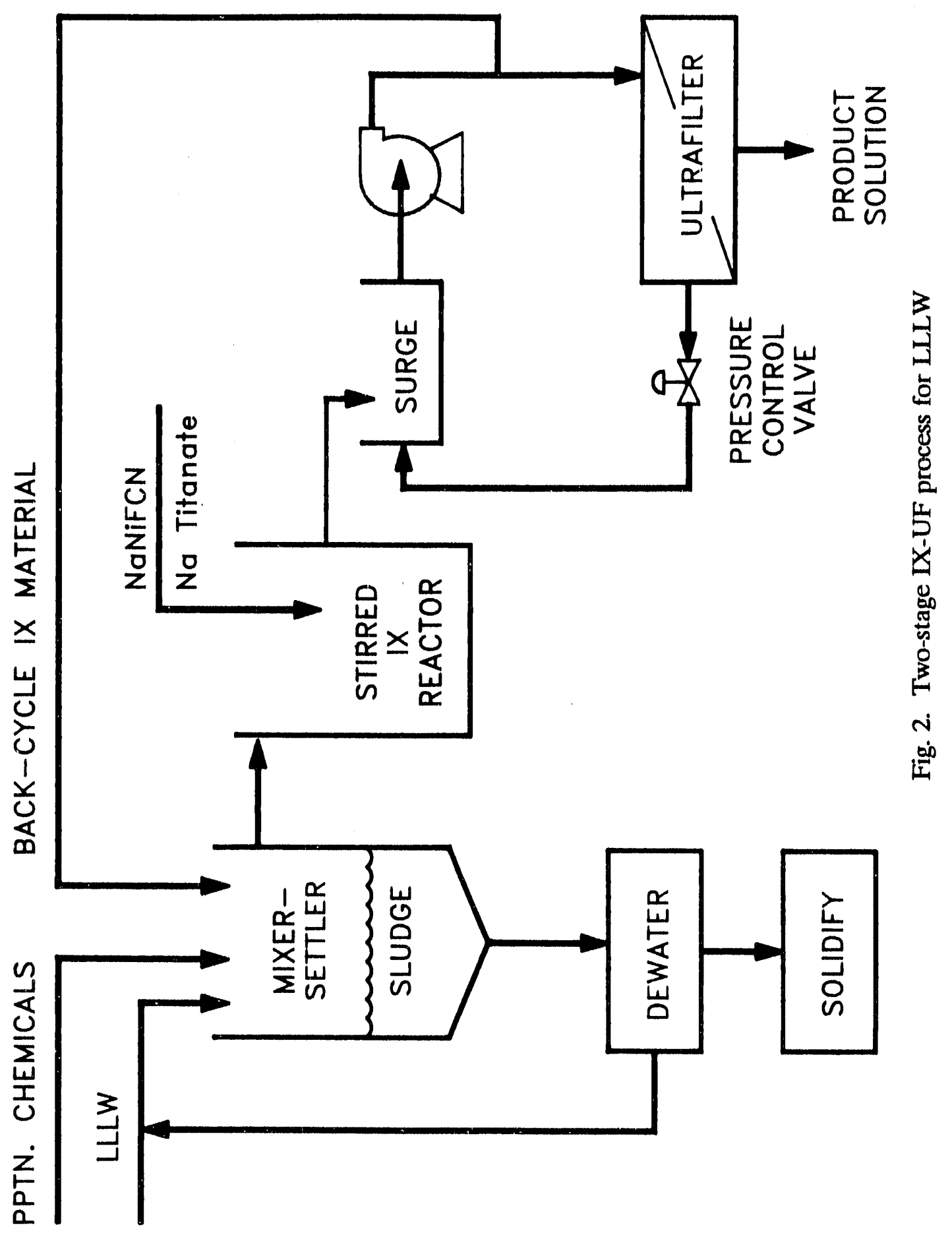


ORNL DWG 91A-240

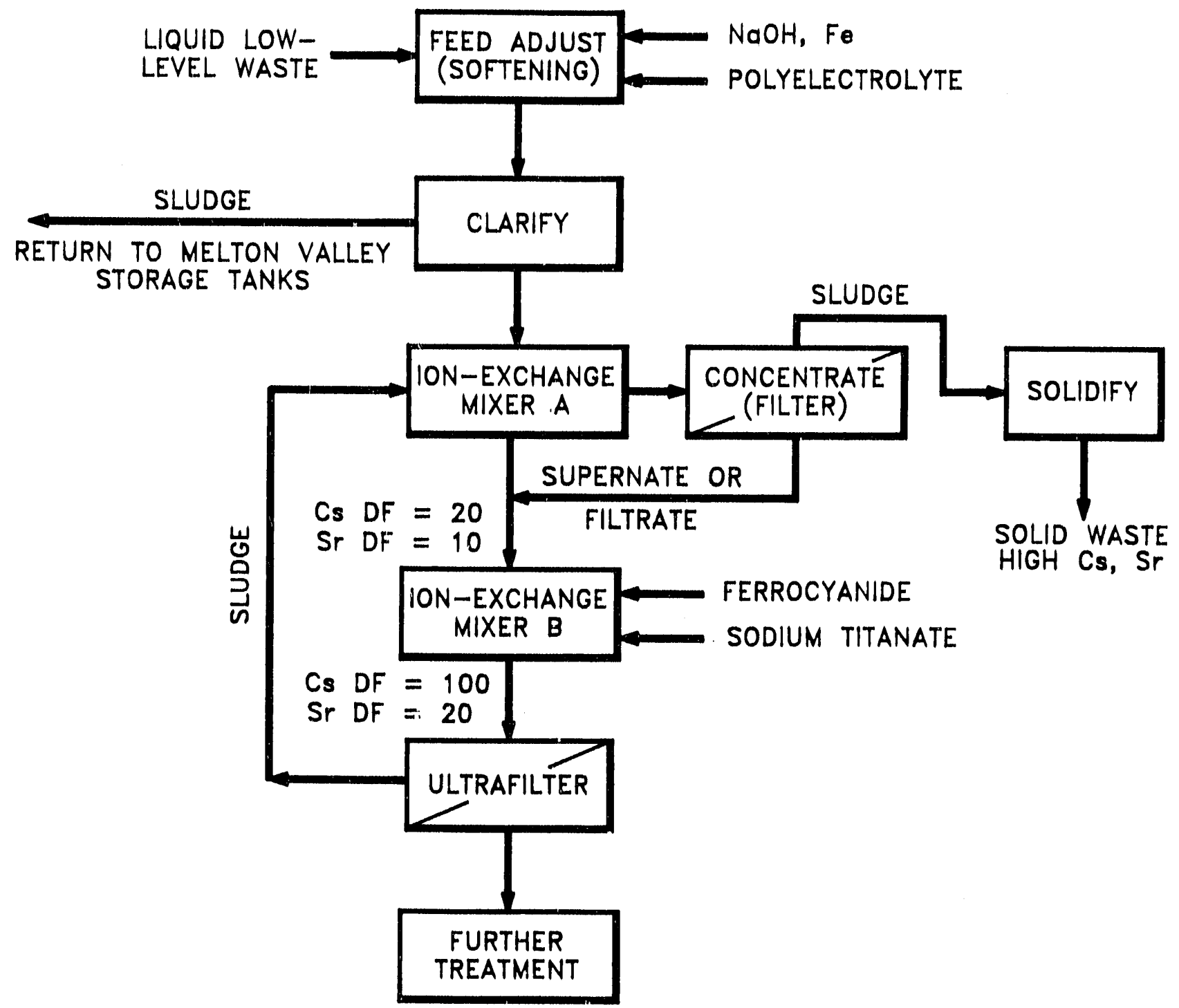

Fig. 3. Supernate batch processing flowsheet (Alternate A) 
ORNL DWG 91A-239

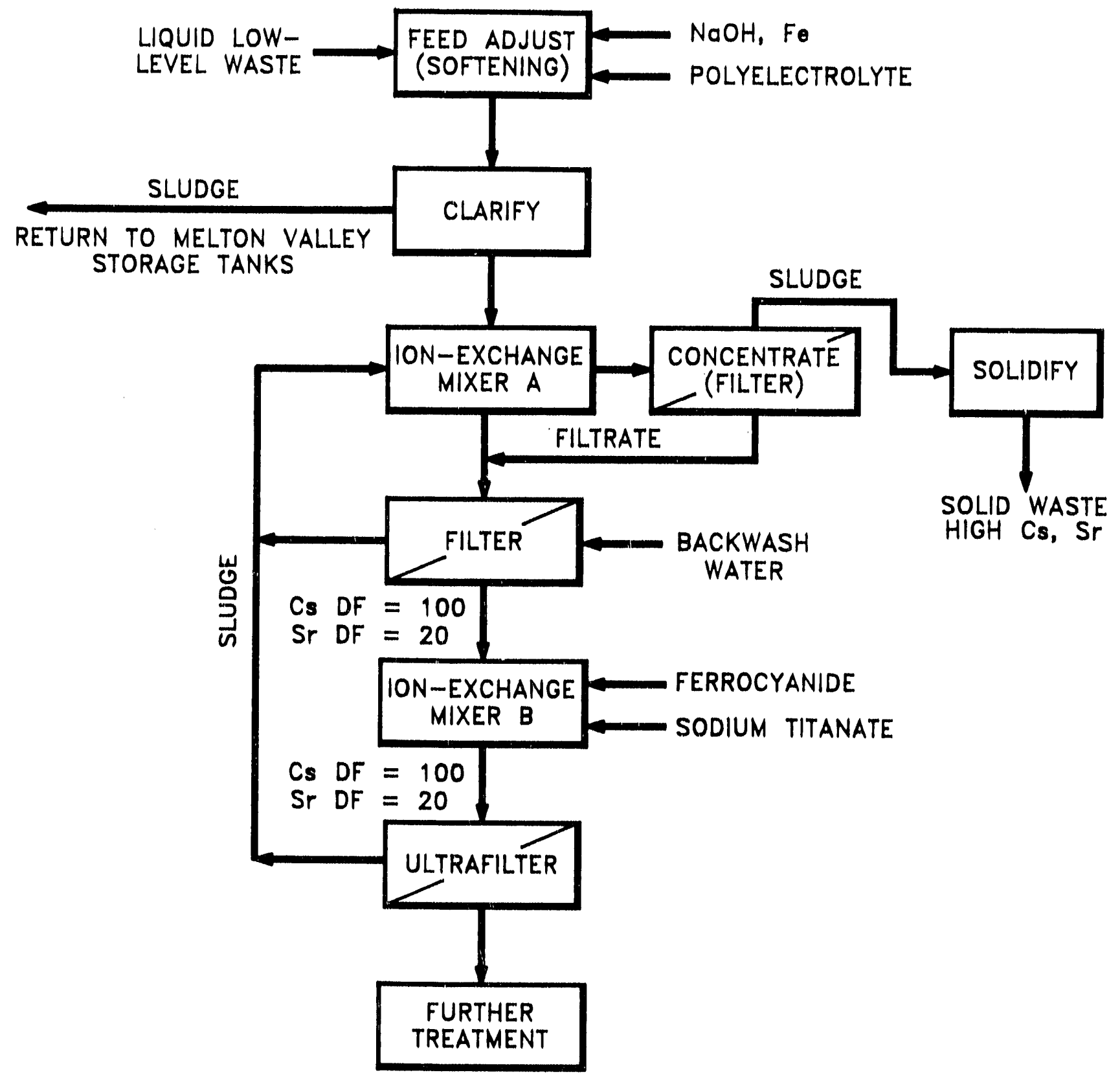

Fig. 4. Supernate batch processing flowsheet (Alternate B) 
It should also be pointed out that quantitative removal of the spent sorbent prior to replacement with new sorbent is not necessary in a batch process. This is illustrated in Table A-3, which is calculated for two successive processing campaigns under the same conditions as Table A-1. After $10,000 \mathrm{~L}$ of product are produced (upper half of Table A-3), $90 \%$ of the sorbent is assumed to be removed as solid waste, new sorbent is added at the rate of $1040 \mathrm{ppm}$ based on the contactor volume (1144 ppm total sorbent including the $10 \%$ heel), and successive batches of waste supernate are processed as before (the lower half of Table A-3). The cumulative DF values are only slightly reduced at the end of the campaign, from 182 to 175 . There is no significant further reduction in subsequent campaign cycles done the same way. This is in marked contrast to the situation with ion-exchange columns, in which serious contamination of effluent streams can result from small amounts of loaded exchanger being left near the bottom of a column when resin is replaced or regenerated. In effect, the advantage of column operation, resulting from the inherent multistage performance, is short-circuited.

When separation stages or processes are used in series in this manner, there is no assurance that such large DFs can actually be obtained because nonequilibrium chemical species present in small concentrations can limit the decontamination process. This is equally true for both batch and column processes. If very large DFs are required, it might be advantageous to use a column process after the first batch separation, which would remove the bulk of the contamination.

A three-stage batch flowsheet that includes ion-exchange columns for further decontamination is illustrated in Fig. 5. As shown in this flowsheet, the sorbent (NaNiFC plus $\mathrm{NaT}$ ) is moved forward one stage (countercurrent to the solution flow) when each batch transfer is made, and the contaminated sorbent (along with any sludge originally entrained with the supernate) is removed only from the first stage; this approach generates the smallest additional quantity of solid waste. The $\mathrm{pH}$ is 10.5 to 11 throughout, so that good cesium DF can be achieved using FCs in each stage. The three-stage batch separation part of this flowsheet was roughly tested (without countercurrent movement of sorbent) using MVST W-26 supernate solution from a sample taken prior to recent transfers. ${ }^{4}$

An alternative way of operating the same flowsheet would be to carry out the first-stage process at a higher $\mathrm{pH}, \approx 13$, possibly with NaT added (Fig. 6). The $\mathrm{pH}$ would then be adjusted to $\sim 10.5$ for the second and third stages; and NaNiFC (and NaT if necessary) would be added to the third stage, transferred to the second, and withdrawn from the 


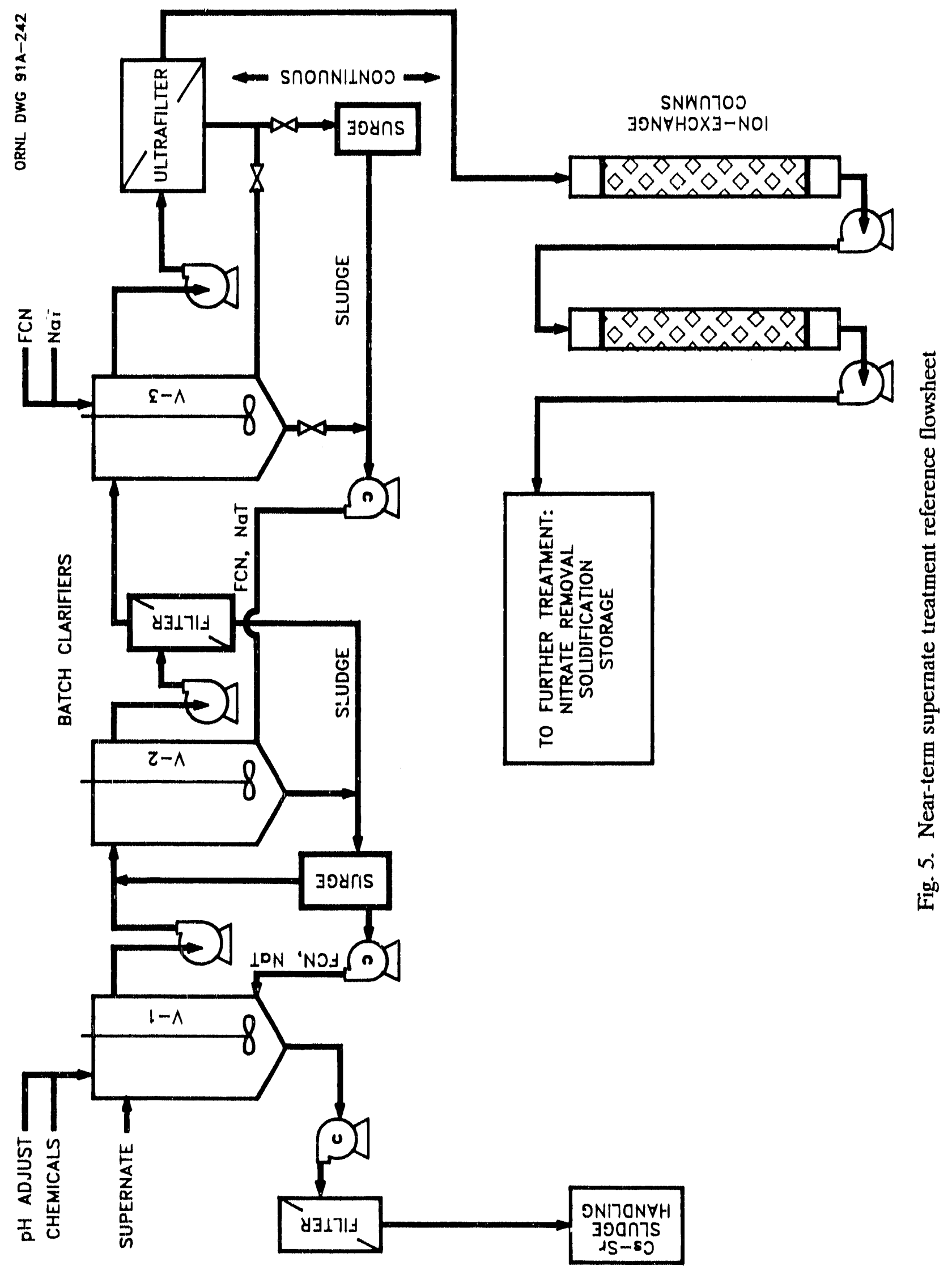


\begin{tabular}{l}
5 \\
\multirow{2}{1}{} \\
$\vdots$ \\
0 \\
0 \\
0 \\
0 \\
$\frac{1}{3}$ \\
0 \\
0
\end{tabular}

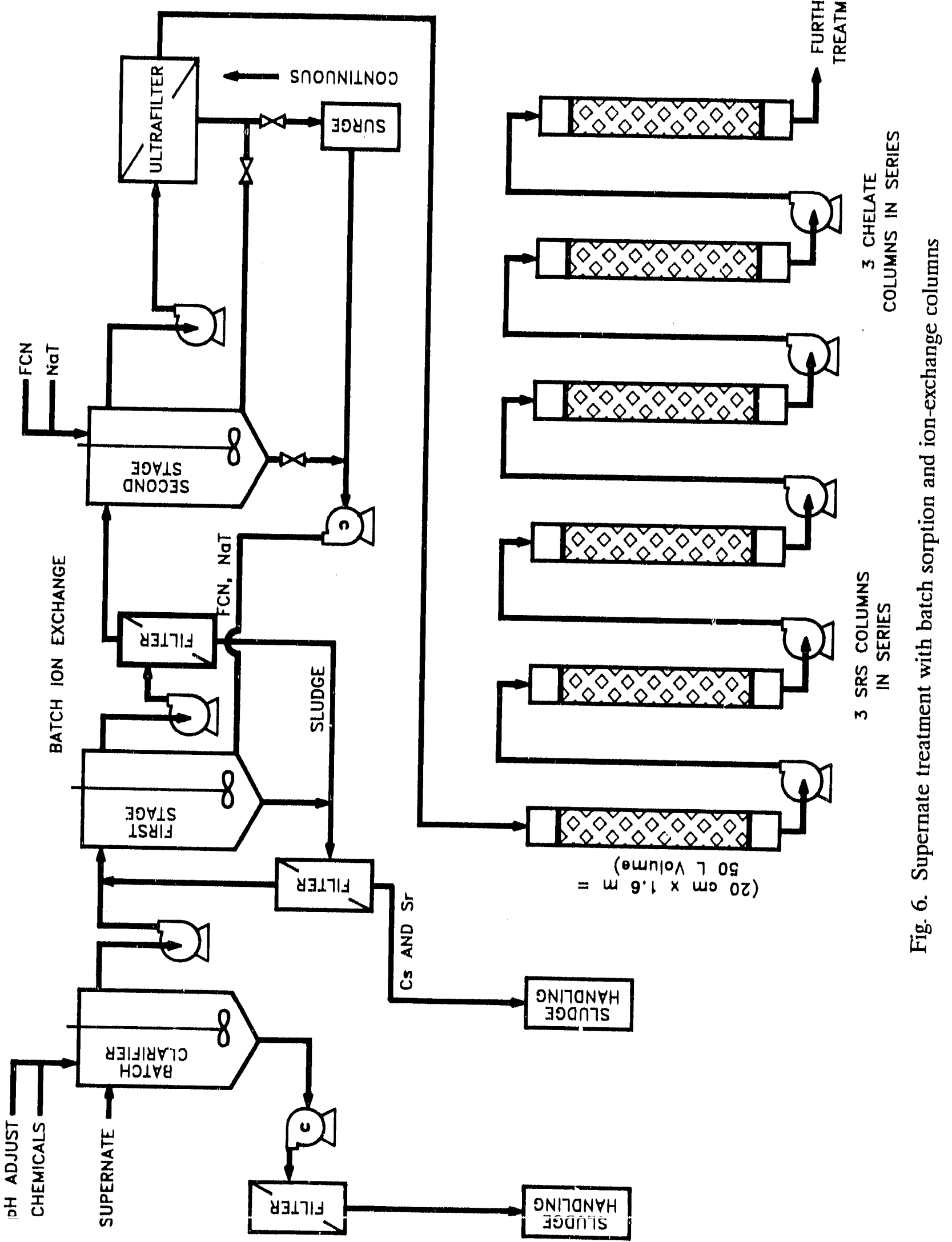


second stage to prevent NaNiFC from entering the high-pH tirst stage. The high $\mathrm{pH}$ of the first stage might be advantageous to give larger DFs for alpha, as well as for ${ }^{90} \mathrm{Sr}$, for which the NaT sorbent is much more effective at high $\mathrm{pH}$. This flowsheet yields two different sludges. These batch separations should give a large DF for both cesium and strontium, in the order of $1 \times 10^{6}$ and $1 \times 10^{5}$, respectively, depending on the amounts of snrbents used; if greater DF is required, ion-exchange columns could be used in series, as shown.

In these cases, the sorbent and other solids would be retained within each batch contactor while many batches of supernate are processed through it. The loaded sorbent would be removed and replaced with new sorbent periodically, or (as shown) the sorbent would be transferred to the next preceding stage. At some point, probably the stage with the highest $\mathrm{pH}$, a very high quality clarification should be carried out. Cross-flow filtration appears to be a practical clarification method, and the pore size of the filter membrane can be selected for each particular application (from several $\mu \mathrm{m}$ down to ultrafilters with pore openings in the $10^{-3}-\mu \mathrm{m}$ range). The filter is the primary maintenance item in this flowsheet. Since the $\gamma$-activity is relatively low downstream from the first stage of cesium separation, hands-on maintenance should be practical there. Shielding will be required where cesium is present, however, so low-maintenance operations are favored in the first stage. It is possible that decantation could be used in the first stage, as illustrated in Fig. 2, but the DF would be smaller. Laboratory experiments suggest the DF would be $\approx 20$ after a $1-\mathrm{d}$ settling period (compared to $\approx 100$ with filtration), but larger-scale testing would be required to verify that.

The use of cross-flow filtration following each batch separation stage would be appropriate for a continuous process as well as for one using repeated batch cycles of feedmixing-clarification. The ion-exchange absorption reactions are relatively fast. As a result, it should be practical to feed continuously, for example, at 1 or a few $\mathrm{L} / \mathrm{min}$, into a mixing vessel of $z 1000 \mathrm{~L}$, and filter continuously at the same rate to produce the decontaminated product.

\subsection{ION-EXCHANGE COLUMN FLOWSHEETS}

Ion-exchange columns containing organic ion-exchange materials, such as SRS resin for cesium and one of the chelating resins for strontium removal, may prove useful after initial clarification of the supernate. As discussed previously, throughputs of a few hundred to a few thousand bed volumes can be expected; and this is adequate for process purposes. 
When properiy operated, ion-exchange columns give the largest DF attainable with the particular solution being treated.

The flow scheme for column operation involves columns in series, opcrated in carousel fashion; that is, as a column is loaded at the front end, it is taken out of service and the next one in series moves to the front. A new column is then placed in the last position in the train. This mode of operation provides much higher utilization of the resin-loading capacity than single-column operation because the loading-band front can be moved below the first column before significant breakthrough occurs from the last column; thus, a column is removed only when all the contained resin is loaded to saturation. Three columns in series for cesium and two or three for strontium are expected to yield adequate results and give much flexibility. Since the $\mathrm{K}_{\mathrm{d}} \mathrm{s}$ for strontium using chelating resins are several times larger than those for cesium with SRS resins, smaller columns would be required, or the same size columns would have to be changed much less frequently.

Clarification followed by three columns of SRS resin in series for cesium removal, followed by two or three columns of chelating resin to remove strontium, would provide excellent removal of cesium and strontium activity in the supernate (Fig. 7). A combinaion of batch absorption followed by ion-exchange columns (as indicated in Figs. 5 and 6) would provide a lower radiation field in the vicinity of the columns, thereby simplifying maintenance; and this should give the maximum DF reasonably attainable. In combination with a nitrate removal and nitric acid recovery process, such a flowsheet might produce an effluent that could be discharged.

The column size can be estimated from the residence time requirement which is related to exchange kinetics. Experimental data have shown that residence times of at least $30 \mathrm{~min}$ are required for good cesium removal with SRS resin in column operations. Assuming a 200-bed-volume capacity with SRS resin, and a flow rate of $76 \mathrm{~L} / \mathrm{h}(20 \mathrm{gal} / \mathrm{h})$, the column volume must be at least $38 \mathrm{~L}$ for a 30 -min residence time. This would treat $160 \mathrm{gal} / \mathrm{d}$ on a basis of $8 \mathrm{~h} / \mathrm{d}$, or $480 \mathrm{gal} / \mathrm{d}$ with $24-\mathrm{h}$ operation. As an example, a volume of $50 \mathrm{~L}$ for each column gives a residence time of $\approx 40 \mathrm{~min}$. Columns of this volume could be sized to be $2.7 \mathrm{~m}$ tall by $15.2 \mathrm{~cm}$ diameter ( $6 \mathrm{in}$. diameter by $9 \mathrm{ft}$ tall) or $1.6 \mathrm{~m}$ tall by $20 \mathrm{~cm}$ diameter ( 8 in. diameter by $5.2 \mathrm{ft}$ tall). Three such columns would be used in series with SRS resin and two or three columns (probably smaller) in series with chelating resin.

Such columns would be expected to last for at least a 200-bed-volume throughput for SRS resin and very much longer for chelating resin. The time between column change-outs would be 133 operating hours ( $5.5 \mathrm{~d}$ at $24 \mathrm{~h} / \mathrm{d}$ or $16.5 \mathrm{~d}$ at $8 \mathrm{~h} / \mathrm{d}$ ) for the $50 \mathrm{~L}$ columns. 


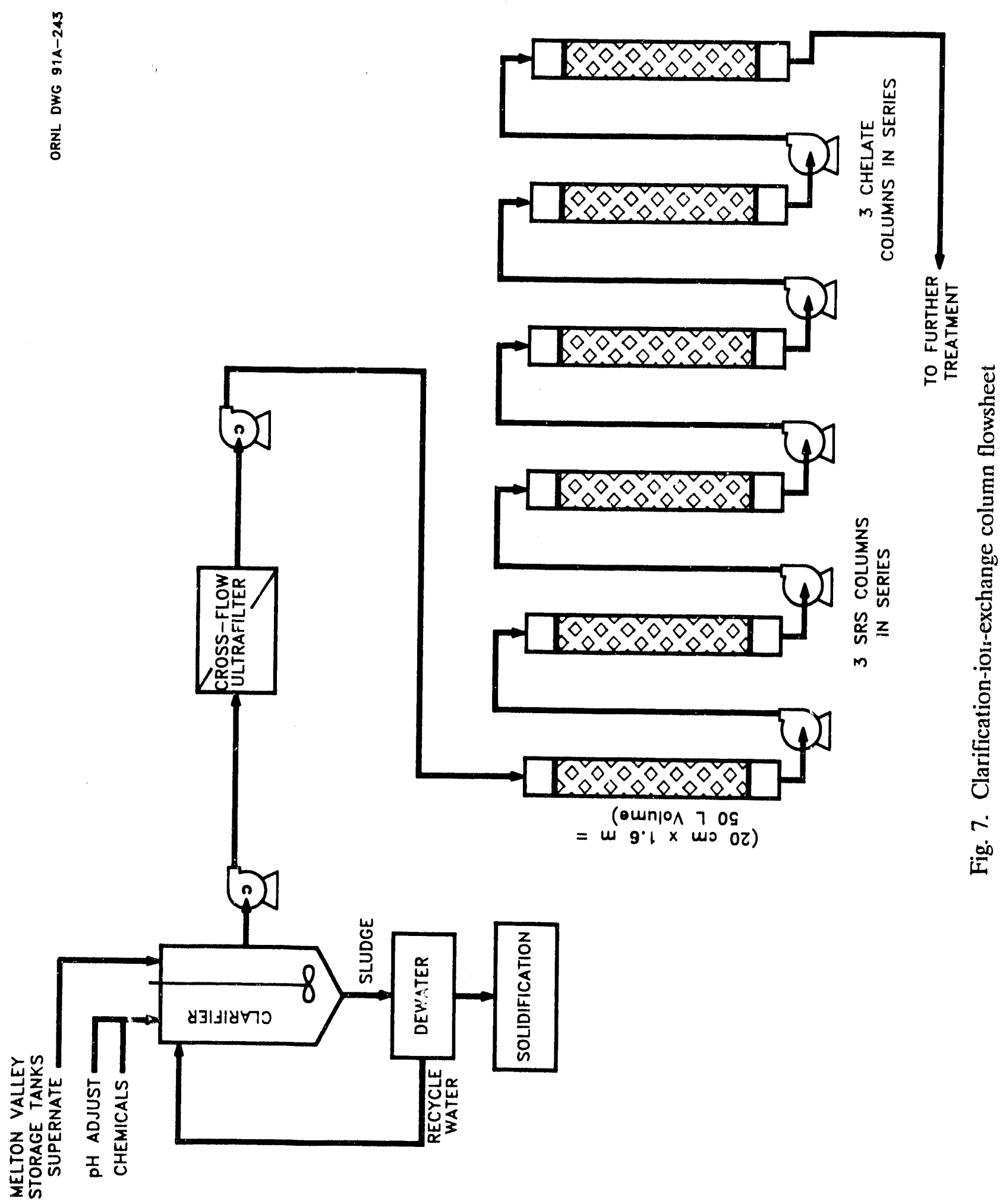


Column change-out or elution would be required $\approx 40$ times for processing the current supernate inventory. Since the $\mathrm{K}_{d} \mathrm{~s}$ for $\mathrm{Sr}$ with the chelating resins are several times larger, a column of chelating resin of the same size would last many weeks to a few months before change-out is required (e.g., $3600 \mathrm{BV} \times 50 \mathrm{~L}+1800 \mathrm{~L} / \mathrm{d} \approx 100 \mathrm{~d}$ ). It would be better to use smaller columns for the chelating resin, within the kinetic limits of the exchange reaction.

As noted earlier, the ion-exchange resins might be regenerated and used for repeated loading cycles, or the resin could be removed and replaced for subsequent cycles. In the former case, regeneration introduces considerable complexity into the system and generates new waste streams that must be recycled or solidified. Also, if not eluted to a satisfactory extent of completion, the subsequent effluent solution will not be adequately decontaminated. The latter case requires quantitative removal of spent resin from the column or use of the column as the disposal container (both of which lead to design constraints), and a system for solidifying the resin as a solid waste. Solidified waste forms containing resins have frequently caused problems because of swelling, but the resin can be burned or thermally decomposed to yield an inert product for solidification. ${ }^{17}$

\section{REFERENCES}

1. M. B. Sears, J. L. Botts, R. N. Ceo, J. J. Ferrada, W. H. Griest, J. M. Keller, and R. J. Schenley, Sampling and Analysis of Radioactive Liquid Wastes and Sludges in the Melton Valley and Evaporator Storage Tanks at ORNL, ORNL/TM-11652, September 1990.

2. D. D. Lee and D. O. Campbell, Low Level Liquid Waste Decontamination Requirements for Disposal Options, ORNL/TM 11799, October 1991.

3. D. O. Campbell, D. D. Lee, and T. A. Dillow, "Low-Level Liquid Waste decontamination by Ion Exchange," Waste Management '90, Vol. 2, R. G. Post, Ed., pp. $389-98$ (1990).

4. D. O. Campbell, D. D. Lee, and T. A. Dillow, Development Studies for Treatment of ORNL Low-Level Liquid Waste, ORNL/TM-11798, November 1991.

5. M. A. Ebra, R. M. Wallace, D. D. Walker, and R. A. Wille, "Tailored Ion Exchange Resins for Combined Cesium and Strontium Removal from Soluble SRP HighLevel Waste," The Scientific Basis for Nuclear Waste Management, S. V. Topp, Ed, p. 632, Elsever (1982).

6. J. P. Bibler, R. M. Wallace, and L. A. Bray, "Testing a New Cesium-Specific Ion Exchange Resin for Decontamination of Alkaline High-Activity Waste," Waste Management '90, Vol. 2, R. G. Post, Ed, pp. $747-51$ (1990). 
7. P. D. D'Entremont and D. D. Walker, "Tank Farm Processing of High-Level Waste for the Defense Waste Processing Facility,"Waste Management '87, Vol. 2, R. G. Post, Ed., pp. 69-73 (1987).

8. W. E. Prout, E. R. Russell, and H. J. Groh, "Ion Exchange Absorption of Cesium by Potassium Hexacyanocobalt(II) Ferrate( (ii), J. Inorg. Nucl. Chem., 27, 473 (1965).

9. E. W. Hooper, B. A. Phillips, S. P. Dagnall, and N. P. Monckton, An Assessment of the Application of Inorganic Ion Exchangers to the Treatment of Intermediate Level Wastes, AERE-R 11088, Atomic Energy Research Establishment, Harwell, 1984.

10. B. A. Phillips and E. W. Hooper, Study of the Behavior of Inorganic Ion Exchangers in the Treatment of Medium Active Effluents, Part I. Preliminary Experimental Work on Absorber Preparation and Performance, AERE-G 2872, Atomic Energy Research Establishment, Harwell, 1988.

11. G. W. Beaven, J. E. Cross, and E. W. Hooper, Study of the Behavior of Inorganic Ion Exchangers in the Treatment of Medium Active Effluents, Part IV. Further Studies on Absorber Performance, AERE-G 4381, Atomic Energy Research Establishment, Harwell, 1988.

12. J. Lehto and R. Harjula, "Separation of Cesium from Nuclear Waste Solutions with Hexacyanoferrate(II)s and ammonium phosphomolybdate," Solvent Extr. Ion Exch., 5(2), 343-52 (1987).

13. E. P. Horwitz, M. L. Dietz, and D. E. Fisher, "SREX: A New Process for the Extraction and Recovery of Strontium from Acidic Nuclear Waste Streams," Solvent Extr. Ion Exch., in press.

14. R. G. Dosch, Final Report on the Application of Titanates, Niobates, and Tantalates to Neutralized Defense Waste Decontamination-Materials, Properties, Physical Forms, and Regereration Techniques, SAND80-1212, Sandia National Lab., 1981.

15. C. W. Beaven, J. E. Cross, and E. W. Hooper, Study of the Behavior of Inorganic Ion Exchangers in the Treatment of Medium Active Effluents, Part V. The Encapsulation of Inorganic Ion Exchangers in Concrete, AERE-G 4421, Atomic Energy Research Establishment, Harwell, 1988.

16. Washington State Department of Ecology and Washington State Department of Health, "Special Report: Ferrocyanide in Single-Shell High-Level Waste Tanks at Hanford," (July 30, 1990).

17. F. R. Chattin, D. E. Benker, M. H. Lloyd, P. B. Orr, R. G. Ross, and J. T. Wiggins, "Preparation of Curium-Americium Oxide Microspheres by Resin-Bead Loading," ACS Symposium Series, No. 161, Transplutonium Elements-Production and Recovery, J. D. Navratil and W. Schulz, Eds., pp. 173-85, American Chemical Society, 1981. 
APPENDIX 
Table A-1. Calculated cesium removal in 1000-L one-stage mixer with successive 5(0)-L feed batches

\begin{tabular}{|c|c|c|c|c|c|c|c|c|c|c|}
\hline $\begin{array}{c}\text { Batch } \\
\text { No. }\end{array}$ & $\begin{array}{l}\text { Volume } \\
\text { feod } \\
\text { in }\end{array}$ & $\begin{array}{l}\text { Volume } \\
\text { total } \\
\text { fed }\end{array}$ & $\begin{array}{l}\text { Total } \\
\text { activity } \\
\text { present }\end{array}$ & $\begin{array}{l}\text { Sorbent } \\
\text { load } \\
\mathrm{xC}_{0}\end{array}$ & $\begin{array}{l}\text { Aq } \\
\text { conc } \\
C / C_{0}\end{array}$ & $\begin{array}{l}\text { Volume } \\
\text { out } \\
\text { (oum) }\end{array}$ & $\begin{array}{l}\text { Total } \\
\text { volume } \\
\text { out }\end{array}$ & $\begin{array}{l}\text { Total } \\
\text { activity } \\
\text { out }\left(x C_{0}\right)\end{array}$ & $\begin{array}{l}\text { Batch } \\
\text { DF }\end{array}$ & $\begin{array}{c}\text { Cumulative } \\
D F\end{array}$ \\
\hline 1 & 1000 & 1000 & 1000 & 999 & $9.61 E-04$ & 500 & 500 & 0.48 & 1041 & 1041 \\
\hline 2 & 500 & 1500 & 1500 & 1498 & $1.44 \mathrm{E}-03$ & 500 & 1000 & 1.20 & 694 & 833 \\
\hline 3 & 500 & 2000 & 1999 & 1997 & $1.92 E-03$ & 500 & 1500 & 2.16 & 521 & 694 \\
\hline 4 & 500 & 2500 & 2498 & 2485 & $2.40 E-03$ & 500 & 2000 & 3.36 & 417 & 595 \\
\hline 5 & 500 & 3000 & 2997 & 2994 & $2.88 E-03$ & 500 & 2500 & 4.80 & 347 & 521 \\
\hline 6 & 500 & 3500 & 3495 & 3482 & $3.36 E-03$ & 500 & 3000 & 6.48 & 298 & 463 \\
\hline 7 & 500 & 4000 & 3994 & 3980 & $3.84 E-03$ & 500 & 3500 & 8.40 & 261 & 417 \\
\hline 8 & 500 & 4500 & 4492 & 4487 & $4.31 \mathrm{E}-03$ & 500 & 4000 & 10.55 & 232 & 379 \\
\hline 8 & 500 & 5000 & 4989 & 4985 & $4.79 \mathrm{E}-03$ & 500 & 4500 & 12.95 & 209 & 347 \\
\hline 10 & 500 & 5500 & 5487 & 5482 & $5.27 E-03$ & 500 & 5000 & 15.59 & 190 & 321 \\
\hline 11 & 500 & 6000 & 5984 & 5979 & $5.75 E-03$ & 500 & 5500 & 18,46 & 174 & 298 \\
\hline 12 & 500 & 6500 & 6482 & 6475 & $6.23 E-03$ & 500 & 6000 & 21.57 & 161 & 278 \\
\hline 13 & 500 & 7000 & 6878 & 6972 & $6.70 E-03$ & 500 & 6500 & 24.93 & 149 & 261 \\
\hline 14 & 500 & 7500 & 7475 & 7468 & $7.18 E-03$ & 500 & 7000 & 28.52 & 139 & 245 \\
\hline 15 & 500 & 8000 & 7971 & 7964 & $7.66 \mathrm{E}-03$ & 500 & 7500 & 32.34 & 131 & 232 \\
\hline 16 & 500 & 8500 & 8468 & 8460 & $8.13 E-03$ & 500 & 8000 & 36.42 & 123 & 220 \\
\hline 17 & 500 & 8000 & 8964 & 8955 & $8.61 \mathrm{E}-03$ & 500 & 8500 & 40.72 & 116 & 209 \\
\hline 18 & 500 & 9500 & 9459 & 9450 & $9.09 E-03$ & 500 & 9000 & 45.26 & 110 & 199 \\
\hline 19 & 500 & 10000 & 9955 & 9945 & 9. $56 \mathrm{E}-03$ & 500 & 9500 & 50.04 & 105 & 190 \\
\hline 20 & 500 & 10500 & 10450 & 10440 & $1.00 \mathrm{E}-02$ & 500 & 10000 & 55.06 & 100 & 182 \\
\hline 21 & 500 & 11000 & 10945 & 10934 & $1.05 \mathrm{E}-02$ & 500 & 10500 & 60.32 & 95 & 174 \\
\hline 22 & 500 & 11500 & 11440 & 11429 & $1.10 \mathrm{E}-02$ & 500 & 11000 & 65.81 & 91 & 167 \\
\hline 23 & 500 & 12000 & 11934 & 11923 & $1.15 E-02$ & 500 & 11500 & 71.54 & 87 & 161 \\
\hline 24 & 500 & 12500 & 12428 & 12417 & $1.19 \mathrm{E}-02$ & 500 & 12000 & 77.51 & 84 & 155 \\
\hline 25 & 500 & 13000 & 12822 & 12910 & $1.24 E-02$ & 500 & 12500 & 83.72 & 81 & 149 \\
\hline 26 & 500 & 13500 & 13416 & 13403 & $1.29 \mathrm{E}-02$ & 500 & 13000 & 90.16 & 78 & 144 \\
\hline 27 & 500 & 14000 & 13910 & 13896 & $1.34 \mathrm{E}-02$ & 500 & 13500 & 96.85 & 75 & 139 \\
\hline 28 & 500 & 14500 & 14403 & 14389 & $1.38 \mathrm{E}-02$ & 500 & 14000 & 103.76 & 72 & 135 \\
\hline 29 & 500 & 15000 & 14896 & 14882 & $1.43 \mathrm{E}-02$ & 500 & 14500 & 110.92 & 70 & 131 \\
\hline 30 & 500 & 15500 & 15389 & 15374 & $1.48 \mathrm{E}-02$ & 500 & 15000 & 118.31 & 68 & 127 \\
\hline 31 & 500 & 16000 & 15882 & 15866 & $1.53 \mathrm{E}-02$ & 500 & 15500 & 125.94 & 66 & 223 \\
\hline 32 & 500 & 16500 & 16374 & 16358 & $1.57 E-02$ & 500 & 16000 & 133.80 & 64 & 120 \\
\hline 33 & 500 & 17000 & 16866 & 16850 & $1.62 E-02$ & 500 & 16500 & 141.90 & 62 & 116 \\
\hline 34 & 500 & 17500 & 17358 & 17341 & $1.67 \mathrm{E}-02$ & 500 & 17000 & 150.24 & 60 & 113 \\
\hline 35 & 500 & 18000 & 17850 & 17833 & $1.71 E-02$ & 500 & 17500 & 158.81 & 58 & 110 \\
\hline 36 & 500 & 18500 & 18341 & 18324 & $1.76 E-02$ & 500 & 18000 & 167.62 & 57 & 107 \\
\hline 37 & 500 & 19000 & 18832 & 18814 & $1.81 E-02$ & 500 & 18500 & 176.67 & 55 & 105 \\
\hline 38 & 500 & 19500 & 19323 & 19305 & $1.86 \mathrm{E}-02$ & 500 & 19000 & 185.95 & 54 & 102 \\
\hline 39 & 500 & 20000 & 19814 & 18795 & $1.90 E-02$ & 500 & 19500 & 195.47 & 53 & 100 \\
\hline 40 & 500 & 20500 & 20305 & 20285 & $1.85 E-02$ & 500 & 20000 & 205.22 & 51 & 97 \\
\hline 41 & 500 & 21000 & 20795 & 20775 & 2. $00 \mathrm{E}-02$ & 500 & 20500 & 215.21 & 50 & 95 \\
\hline 42 & 500 & 21500 & 21285 & 21264 & $2.04 E-02$ & 500 & 21000 & 225.43 & 49 & 93 \\
\hline 43 & 500 & 22000 & 21775 & 21754 & $2.09 E-02$ & 500 & 21500 & 235.89 & 48 & 91 \\
\hline 44 & 500 & 22500 & 22264 & 22243 & $2.24 \mathrm{E}-02$ & 500 & 22000 & 246.58 & 47 & 89 \\
\hline
\end{tabular}


Table A-2 Calculated cesium removal in second-stage 1000-L mixer with successive $500 \mathrm{~L}$ feed batches from first-stage separation shown in Table A-1*

\begin{tabular}{|c|c|c|c|c|c|c|c|c|c|}
\hline $\begin{array}{l}\text { Batoh } \\
\text { No. }\end{array}$ & $\begin{array}{l}\text { Volume } \\
\text { feed } \\
\text { in }\end{array}$ & $\begin{array}{l}\text { Total } \\
\text { acttuity } \\
\text { present }\end{array}$ & $\begin{array}{c}\text { Sorbent } \\
\text { load } \\
x \mathrm{C}_{0}\end{array}$ & $\begin{array}{c}\text { Aq } \\
\text { oono } \\
C / C_{0}\end{array}$ & $\begin{array}{l}\text { Volume } \\
\text { out }\end{array}$ & $\begin{array}{l}\text { Total } \\
\text { volume } \\
\text { out }\left(\mathrm{xC}_{0}\right)\end{array}$ & $\begin{array}{l}\text { Total } \\
\text { activity } \\
\text { out }\left(x C_{0}\right)\end{array}$ & $\begin{array}{c}\text { Batch } \\
\text { DF }\end{array}$ & $\begin{array}{c}\text { Cumulative } \\
\text { DF }\end{array}$ \\
\hline 1 & 500 & 0.48 & 0.48 & $4,61 E-07$ & 0 & 0 & & & \\
\hline 2 & 500 & 1.20 & 1.20 & $1.15 E-06$ & 500 & 500 & $5.77 E-04$ & 867111 & 867111 \\
\hline 3 & 500 & 2.16 & 2.16 & $2.07 E-06$ & 500 & 1000 & $1.61 E-03$ & 481945 & 619544 \\
\hline 4 & 500 & 3.36 & 3.36 & $3.23 E-06$ & 500 & 1500 & $3.23 E-03$ & 308942 & 464785 \\
\hline 5 & 500 & 4.80 & 4.79 & $4.61 E-06$ & 500 & 2000 & $5.53 E-03$ & 217038 & 361596 \\
\hline 6 & 500 & 6.47 & 6.47 & $6.22 E-06$ & 500 & 2500 & 8. $64 \mathrm{E}-03$ & 160825 & 288352 \\
\hline 7 & 500 & 8.39 & 8.38 & $8.06 E-06$ & 500 & 3000 & $1.27 \mathrm{E}-02$ & 124108 & 236803 \\
\hline 8 & 500 & 10.54 & 10.53 & $1.01 E-05$ & 500 & 3500 & $1.77 \mathrm{E}-02$ & 98755 & 197386 \\
\hline 8 & 500 & 12.93 & 12.82 & $1.24 E-05$ & 500 & 4000 & $2.39 E-02$ & 80494 & 167061 \\
\hline 10 & 500 & 15.56 & 15.55 & $1.48 E-05$ & 500 & 4500 & $3.14 \mathrm{E}-02$ & 66894 & 143231 \\
\hline 11 & 500 & 18.43 & 18.41 & $1.77 \mathrm{E}-05$ & 500 & 5000 & $4.03 E-02$ & 56488 & 124164 \\
\hline 12 & 500 & 21.53 & 21.51 & $2.07 E-05$ & 500 & 5500 & $5.06 E-02$ & 48344 & 108670 \\
\hline 13 & 500 & 24.87 & 24.85 & $2.39 E-05$ & 500 & 6000 & $6.26 E-02$ & 41850 & 95909 \\
\hline 14 & 500 & 28.45 & 28.43 & $2.73 \mathrm{E}-05$ & 500 & 6500 & $7.62 \mathrm{E}-02$ & 36587 & 85274 \\
\hline 15 & 500 & 32.27 & 32.24 & $3.10 E-05$ & 500 & 7000 & $9.17 E-02$ & 32261 & 76316 \\
\hline 16 & 500 & 36.32 & 36.28 & $3.49 E-05$ & 500 & 7500 & $1.09 E-01$ & 28662 & 68701 \\
\hline 17 & 500 & 40.61 & 40.57 & $3.80 \mathrm{E}-05$ & 500 & 8000 & $1.29 \mathrm{E}-01$ & 25636 & 62173 \\
\hline 18 & 500 & 45.13 & 45.09 & $4.34 E-05$ & 500 & 8500 & $1.50 E-01$ & 23066 & 56535 \\
\hline 19 & 500 & 49.89 & 48.84 & $4.79 E-05$ & 500 & 9000 & $1.74 \mathrm{E}-01$ & 20866 & 51632 \\
\hline 20 & 500 & 54.89 & 54.83 & $5.27 E-05$ & 500 & 9500 & $2.01 E-01$ & 18967 & 47340 \\
\hline 21 & 500 & 60.12 & 60.06 & $5.77 E-05$ & 500 & 10000 & $2.30 E-01$ & 17316 & 43564 \\
\hline 22 & 500 & 65.58 & 65.52 & $6.30 E-05$ & 500 & 10500 & $2.61 E-01$ & 15873 & 40222 \\
\hline 23 & 500 & 71.28 & 71.21 & $6.85 E-05$ & 500 & 11000 & $2.95 E-01$ & 14604 & 37252 \\
\hline 24 & 500 & 77.22 & 77.14 & $7.42 \mathrm{E}-05$ & 500 & 11500 & $3.32 \mathrm{E}-01$ & 13481 & 34600 \\
\hline 25 & 500 & 83.39 & 83.31 & B. $01 E-05$ & 500 & 12000 & $3.72 E-01$ & 12484 & 32221 \\
\hline 26 & 500 & 89.78 & 88.71 & $8.63 E-05$ & 500 & 12500 & $4.16 E-01$ & 11593 & 30080 \\
\hline 27 & 500 & 96.43 & 96.34 & $9.26 E-05$ & 500 & 13000 & $4.62 E-01$ & 10795 & 2.8146 \\
\hline 28 & 500 & 103.30 & 103.20 & $9.92 \mathrm{E}-05$ & 500 & 13500 & $5.11 E-01$ & 10077 & 26394 \\
\hline 29 & 500 & 110.41 & 110.30 & $1.06 E-04$ & 500 & 14000 & $5.65 E-01$ & 9429 & 24800 \\
\hline 30 & 500 & 117.74 & 117.63 & $1.13 E-04$ & 500 & 14500 & $6.21 E-01$ & 8841 & 23347 \\
\hline 31 & 500 & 125.32 & 125.20 & $1.20 \mathrm{E}-04$ & 500 & 15000 & $6.81 E-01$ & 8307 & 22018 \\
\hline 32 & 500 & 133.12 & 132.99 & $1.28 \mathrm{E}-04$ & 500 & 15500 & $7.45 \mathrm{E}-01$ & 7820 & 20800 \\
\hline 33 & 500 & 141.16 & 141.02 & $1.36 \mathrm{E}-04$ & 500 & 16000 & $8.13 E-01$ & 7375 & 19680 \\
\hline 34 & 500 & 149.43 & 149.28 & $1.44 E-04$ & 500 & 16500 & $8.85 E-01$ & 6967 & 18649 \\
\hline 35 & 500 & 157.93 & 157.78 & $1.52 \mathrm{E}-04$ & 500 & 17000 & $9.61 E-01$ & 6592 & 17697 \\
\hline 36 & 500 & 166.66 & 166.50 & $1.60 \mathrm{E}-04$ & 500 & 17500 & $1.04 \mathrm{E}+00$ & 6246 & 16816 \\
\hline 37 & 500 & 175.63 & 175.46 & $1.69 \mathrm{E}-04$ & 500 & 18000 & $1.13 E+00$ & 5927 & 16000 \\
\hline 38 & 500 & 184.82 & 184.65 & $1.78 E-04$ & 500 & 18500 & $1.21 \mathrm{E}+00$ & 5632 & 15241 \\
\hline 39 & 500 & 194.25 & 194.07 & $1.87 E-04$ & 500 & 19000 & $1.31 k+00$ & 5359 & 14536 \\
\hline 40 & 500 & 203.91 & 203.72 & $1.96 \mathrm{E}-04$ & 500 & 19500 & $1.41 E+00$ & 5105 & 13879 \\
\hline 41 & 500 & 213.80 & 213.60 & $2.05 E-04$ & 500 & 20000 & $1.51 E+00$ & 4869 & 13265 \\
\hline 42 & 500 & 223.92 & 223.71 & $2.15 E-04$ & 500 & 20500 & $1.62 \mathrm{E}+00$ & 4648 & 12691 \\
\hline 43 & 500 & 234,27 & 234.05 & $2,25 E-04$ & 500 & 21000 & $1,73 E+00$ & 4444 & 12154 \\
\hline
\end{tabular}


Table A-3. Calculated cesium removal in one-stage 1000-L mixer with successive $500 \mathrm{~L}$ feed batches"

\begin{tabular}{|c|c|c|c|c|c|c|c|c|c|c|c|}
\hline \multirow{2}{*}{$\begin{array}{c}\text { Batoh } \\
\text { No. }\end{array}$} & \multirow{2}{*}{$\begin{array}{l}\text { Volume } \\
\text { feed } \\
\text { in }\end{array}$} & \multirow{2}{*}{$\begin{array}{l}\text { Volume } \\
\text { total } \\
\text { fed }\end{array}$} & \multirow{2}{*}{$\begin{array}{l}\text { Total } \\
\text { aotivity } \\
\text { present }\end{array}$} & \multirow{2}{*}{$\begin{array}{l}\text { Sorbent } \\
\text { load } \\
\times C_{0}\end{array}$} & \multirow{2}{*}{$\begin{array}{l}A q \\
\text { oono } \\
C / C_{D}\end{array}$} & \multirow{2}{*}{$\begin{array}{l}\text { Volume } \\
\text { out }\end{array}$} & \multirow{2}{*}{$\begin{array}{l}\text { Total } \\
\text { vol. } \\
\text { out }\end{array}$} & \multirow{2}{*}{$\begin{array}{l}\text { Total } \\
\text { aotivity } \\
\text { out }\left(x C_{0}\right)\end{array}$} & \multirow{2}{*}{$\begin{array}{l}\text { Batoh } \\
\text { DF }\end{array}$} & \multicolumn{2}{|c|}{ Cumulat 1ve } \\
\hline & & & & & & & & & & $\begin{array}{c}\overline{D F} \\
(0 y \circ 10)\end{array}$ & $\begin{array}{c}D F \\
(\text { total) }\end{array}$ \\
\hline 1 & 1000 & 1000 & 1000 & 998 & $8.61 E-04$ & 500 & 500 & 0.48 & 1041 & 1041 & 8 \\
\hline 2 & 500 & 1500 & 1500 & 1498 & $1.44 E-03$ & 500 & 1000 & 1.20 & 694 & 833 & a \\
\hline 3 & 500 & 2000 & 1899 & 1997 & 1. $92 E-03$ & 500 & 1500 & 2.16 & 521 & 694 & m \\
\hline 4 & 500 & 2500 & 2498 & 2495 & $2,40 E-03$ & 500 & 2000 & 3.36 & 417 & 595 & $\theta$ \\
\hline 5 & 500 & 3000 & 2997 & 2994 & $2.88 \mathrm{E}-03$ & 500 & 2500 & 4.80 & 347 & 521 & \\
\hline 6 & 500 & 3500 & 3485 & 3492 & $3.36 \mathrm{E}-03$ & 500 & 3000 & 6.48 & 298 & 463 & $\mathbf{a}$ \\
\hline 7 & 500 & 4000 & 3994 & 3990 & $3.84 E-03$ & 500 & 3500 & 8.40 & 261 & 417 & $\mathbf{s}$ \\
\hline 8 & 500 & 4500 & 4492 & 4487 & $4.31 E-03$ & 500 & 4000 & 10.55 & 232 & 379 & \\
\hline 9 & 500 & 5000 & 4989 & 4985 & $4.79 E-03$ & 500 & 4500 & 12.85 & 209 & 347 & $\mathrm{c}$ \\
\hline 10 & 500 & 5500 & 5487 & 5482 & $5.27 E-03$ & 500 & 5000 & 15.59 & 190 & 321 & $y$ \\
\hline 11 & 500 & 6000 & 5984 & 5978 & $5.75 E-03$ & 500 & 5500 & 18.46 & 174 & 298 & c \\
\hline 12 & 500 & 6500 & 6482 & 6475 & $6.23 E-03$ & 500 & 6000 & 21.57 & 161 & 278 & 1 \\
\hline 13 & 500 & 7000 & 6978 & 6972 & $6.70 \mathrm{E}-03$ & 500 & 6500 & 24.93 & 149 & 261 & $\mathbf{e}$ \\
\hline 14 & 500 & 7500 & 7475 & 7468 & $7.18 \mathrm{E}-03$ & 500 & 7000 & 28.52 & 139 & 245 & \\
\hline 15 & 500 & 8000 & 7971 & 7964 & $7.66 \mathrm{E}-03$ & 500 & 7500 & 32.34 & 131 & 232 & $D$ \\
\hline 16 & 500 & 8500 & 8468 & 8460 & $8.13 E-03$ & 500 & 8000 & 36.41 & 123 & 220 & $\mathrm{~F}$ \\
\hline 17 & 500 & 9000 & 8964 & 8955 & $8.61 E-03$ & 500 & 8500 & 40.72 & 116 & 209 & \\
\hline 18 & 500 & 9500 & 8459 & 9450 & $9.08 E-03$ & 500 & 9000 & 45.26 & 110 & 189 & \\
\hline 18 & 500 & 10000 & 9955 & 9945 & $9.56 \mathrm{E}-03$ & 500 & 9500 & 50.04 & 105 & 180 & \\
\hline 20 & 500 & 10500 & 10450 & 10440 & $1.00 \mathrm{E}-02$ & 500 & 10000 & 55.06 & 100 & 182 & \\
\hline
\end{tabular}

Cycle 2: Process through batch 20 of Table 3 ; Remove $90 \mathrm{z}$ of sorbent; Add new sorbent; Continue.

\begin{tabular}{|c|c|c|c|c|c|c|c|c|c|c|c|}
\hline 1 & 1000 & 1000 & 2044 & 2042 & $1.79 \mathrm{E}-03$ & 500 & 500 & 0.89 & 560 & 560 & 188 \\
\hline 2 & 500 & 1500 & 2543 & 2541 & $2.22 \mathrm{E}-03$ & 500 & 1000 & 2.00 & 450 & 499 & 193 \\
\hline 3 & 500 & 2000 & 3042 & 3039 & $2.66 \mathrm{E}-03$ & 500 & 1500 & 3.33 & 376 & 450 & 197 \\
\hline 4 & 560 & 2500 & 3541 & 3538 & $3.08 E-03$ & 500 & 2000 & 4.88 & 323 & 410 & 200 \\
\hline 5 & 500 & 3000 & 4039 & 4036 & $3.53 E-03$ & 500 & 2500 & 6.64 & 283 & 376 & 203 \\
\hline 6 & 500 & 3500 & 4537 & 4533 & $3.96 \mathrm{E}-03$ & 500 & 3000 & 8.62 & 252 & 348 & 204 \\
\hline 7 & 500 & 4000 & 5035 & 5031 & $4.40 E-03$ & 500 & 3500 & 10.82 & 227 & 323 & 205 \\
\hline 8 & 500 & 4500 & 5533 & 5528 & $4.83 E-03$ & 500 & 4000 & 13.24 & 207 & 302 & 205 \\
\hline 9 & 500 & 5000 & 6031 & 8025 & $5.27 E-03$ & 500 & 4500 & 15.87 & 190 & 284 & 204 \\
\hline 10 & 500 & 5500 & 6528 & 6522 & $5.70 E-03$ & 500 & 5000 & 18.72 & 175 & 267 & 203 \\
\hline 11 & 500 & 6000 & 7025 & 7019 & $6.14 E-03$ & 500 & 5500 & 21.78 & 163 & 252 & 202 \\
\hline 12 & 500 & 6500 & 7522 & 7516 & $6.57 E-03$ & 500 & 6000 & 25.07 & 152 & 239 & 200 \\
\hline 13 & 500 & 7000 & 8019 & 8012 & $7.005-03$ & 500 & 6500 & 28.58 & 143 & 227 & 197 \\
\hline 14 & 500 & 7500 & 8515 & 8508 & $7.44 E-03$ & 500 & 7000 & 32.29 & 134 & 217 & 195 \\
\hline 15 & 500 & 8000 & 9012 & 8004 & $7.87 E-03$ & 500 & 7500 & 36.23 & 127 & 207 & 192 \\
\hline 16 & 500 & 8500 & 9508 & 9499 & $8.30 E-03$ & 500 & 8000 & 40,38 & 120 & 198 & 189 \\
\hline 17 & 500 & 8000 & 10004 & 8995 & $8.74 E-03$ & 500 & 8500 & 44.75 & 114 & 190 & 185 \\
\hline 18 & 500 & 9500 & 10499 & 10490 & $8.17 E-03$ & 500 & 8000 & 48.34 & 100 & 182 & 182 \\
\hline 19 & 500 & 10000 & 10995 & 10985 & $8.60 \mathrm{E}-03$ & 500 & 9500 & 54.14 & 104 & 175 & 179 \\
\hline 20 & 500 & 10500 & 11490 & 11480 & $1,00 \mathrm{E}-02$ & 500 & 10000 & 59,15 & 100 & 169 & 175 \\
\hline
\end{tabular}




\section{INTERNAL DISTRIBUTION}

1. H. L. Adair

2. J. M. Begovich

3. J. T. Bell

4. J. B. Berry

5. W. D. Bond

6. C. H. Brown, Jr.

7. C. O. Campbell

8. R. M. Canon

9. E. D. Collins

10. K. W. Cook

11. A. G. Croff

12. T. A. Dillow

13. S. M. DePaoli

14. C. P. East

15. B. Z. Egan

16. W. Fulkerson

17. R. K. Genung

18. J. R. Hightower

19. L. Holder

20. E. K. Johnson

21. C. M. Kendrick

22. T. E. Kent
23. J. R. Lawson

24-25. D. D. Lee

26. J. J. Maddox

27. R. C. Mason

28. A. J. Mattus

29. L. E. McNeese

30. L. J. Mezga

31. J. J. Perona

32. D. J. Peterson

33. D. R. Reichle

34. S. M. Robinson

35. T. F. Scanlan

36. C. B. Scott

37. M. G. Stewart

38. P. A. Taylor

39. J. R. Trabalka

40. D. W. Turner

41. E. L. Youngblood

42. Cen. Res. Library

43. Doc. Ref. Section

44-45 Lab Records

46. Lab Records. R.C.

47. ORNL Pat. Sect.

\section{EXTERNAL DISTRIBUTION}

48. Office of Assistant Manager, Energy Research and Jevelopment, DOE-OR, P. O. Box 2001, Oak Ridge, TN 37831-8600

4958. Office of Scientific and Technical Information, P. O. Box 62, Oak Ridge, TN 37831 

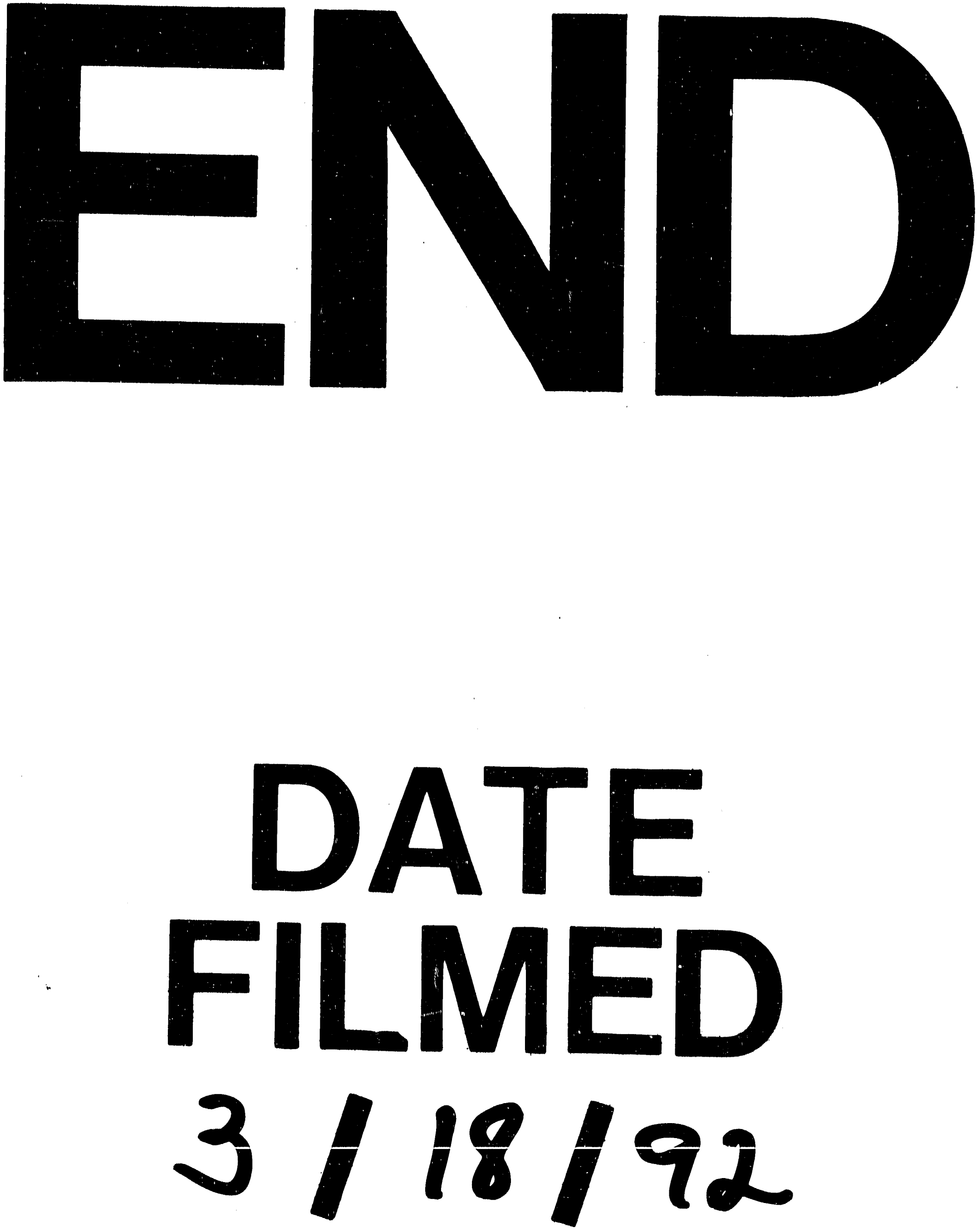
